\title{
Losses, hopes, and expectations for sustainable futures after COVID
}

\author{
Stephan Lewandowsky (D) ${ }^{1,2 \otimes}$, Keri Facer (i) ${ }^{1}$ \& Ullrich K. H. Ecker (i) ${ }^{2}$
}

The COVID-19 pandemic has caused immense distress but also created opportunity for radical change. Two main avenues for recovery from the pandemic have been discussed: A "back to normal" that foregrounds economic recovery, and a sustainable and progressive "build back better" approach that seeks to address global problems such as inequality and climate change. The article reports two experiments conducted on representative British and American samples ( $N=600$ and $N=800$, respectively, for the two experiments) that show that people in both countries overall prefer a progressive future to a return to normal, although that preference is stronger on the political left and center-left with ambivalence prevailing on the right. However, irrespective of political leanings, people consider a return to normal more likely than a progressive future. People also mistakenly believe that others want the progressive scenarios less, and the return to normal more, than they actually do. The divergence between what people want and what they think others want represents an instance of pluralistic ignorance, which arises when public discourse is not reflecting people's actual opinions. Publicizing public opinion is thus crucial to facilitate a future with broad support. In additional open-ended items, participants cited working from home, reduced commuting, and a collective sense of civility as worth retaining post pandemic.

\footnotetext{
${ }^{1}$ University of Bristol, Bristol, UK. ${ }^{2}$ University of Western Australia, Perth, WA, Australia. ${ }^{凶}$ email: stephan.lewandowsky@bristol.ac.uk
} 
T he COVID-19 crisis has turned the world upside down, exposing deep weaknesses in existing systems and structures (Goede, 2020). The disruption of the global economy has damaged or threatened the livelihoods of countless people (Bartik et al., 2020; Bonaccorsi et al., 2020), while also highlighting other socio-economic issues, such as poor working conditions and precarious remuneration of essential workers and the vulnerability of minorities. Social restrictions to control the pandemic likewise disproportionately impacted women, single parents, young people, and migrants (Greenaway et al., 2020; The Lancet, 2020; van Barneveld et al., 2020; Wenham et al., 2020).

Even though vaccinations have been rolled out on a large scale in most developed countries, the pandemic will continue to be a significant public health concern, and the economic fallout will be felt for some time to come (Paltiel et al., 2020). Societies are therefore faced with difficult political decisions about how to recover from the crisis and what future pathway to embark on. Our aim is to inform this debate by exploring the public's attitudes towards possible futures in the United States and the United Kingdom. We are particularly concerned with three aspects of public attitudes: First, what people want for themselves, which should inform future planning by governments. Second, what people consider likely to happen, which can identify people's perceptions of current power structures in society. Third, what people think others want, which reveals how well people are calibrated to the opinion landscape in which they live. We focus on four possible futures that are representative of a broad range of opinions about the recovery that have appeared in public discussion and the academic literature.

In the early stages of the pandemic (March-July 2020), a rapid return to normal was an omnipresent catch phrase, perhaps reflecting a deep-seated desire to avert the worst of the pandemic and reflecting the hope that the virus might be quickly brought under control after the first wave. However, alternative slogans such as build back better (Hamann, 2020; Shepherd, 2020) have also gained traction with promises of a brighter, more equitable, and more sustainable future based on radical change. Notwithstanding their broad usage, the slogans remain ambiguous and each can describe many different future paths.

We identify two principal dimensions that have shaped the debate between building back better and returning to normal. The first dimension revolves around sustainability and climate change. Some calls to build back better have invoked a green new deal (Rosner, 2020), in part motivated by the reduced carbon emissions occasioned by the pandemic. The European Union seems poised to take this route, with a Green Deal recovery package (European Commission, 2020). In the US, the mayors of Boston and New Orleans have similarly argued that climate action must be a central component of any recovery from COVID-19 (Walsh and Cantrell, 2020), a stance mirrored by the mayor of London who announced his own Green New Deal in November 2020 (Mayor of London, 2020). A build back better recovery has also been backed by members of the medical community, with calls to use the crisis as an opportunity to address imbalances and build stronger medical systems (Clark \& Gruending, 2020) and to tackle climate change, the gravest public health threat of the 21st century (Harmer, 2021). Others have strongly opposed any green recovery, arguing that what is needed is immediate economic relief and that climate policy can come later (Temple, 2020), a stance that has been shown to reduce support for climate-change mitigation in US residents (Ecker et al., 2020). Coverage in agenda-setting US media (New York Times and Wall Street Journal) has been shown to paint the Green New Deal, put before Congress in early 2019, as a dangerous policy proposed by Millennial extremists (Morris, 2021). The debate is ongoing, with opposing positions along this dimension being clearly articulated.
The second dimension revolves around the curtailing of freedoms and civil liberties during the pandemic. The social restrictions aimed at slowing the pandemic, such as lockdowns, school closures, and cancellations of social and sporting events, have abrogated people's rights to an extent that is unprecedented in contemporary liberal democracies (Grogan, 2020). Although these social restrictions were demonstrably successful (Haug et al., 2020; Robinson et al., 2020), they have not only negatively impacted mental health at scale (Every-Palmer et al., 2020; Serafini et al., 2020; Xiong et al., 2020) but have also evoked concerns that these policies might trigger a slow authoritarianization, and that social restrictions are harbingers of an authoritarian pandemic (Thomson \& Ip, 2020). These concerns are amplified by the fact that numerous indicators suggest that democracy is in retreat and under threat worldwide (Freedom House, 2020; Lührmann \& Lindberg, 2020), including in Europe. In 2020, The Economist's democracy index determined that one E.U. member state, Hungary, was no longer a democracy (Economist Intelligence Unit, 2020). The Hungarian government has also used the pandemic as an opportunity to grant itself emergency powers (Stott et al., 2020). In the UK, by contrast, policing of socialdistancing measures was mainly based on the concepts of engage, explain, encourage (Stott et al., 2020), emphasizing the diversity in government responses even in light of the need for social distancing. In a comparison across European countries, those that already experienced democractic backsliding also experienced further concentrations of power (Engler et al., 2021). Although an authoritarian advantage (Maravall, 1994) has been surmised during the pandemic, based in part on China's successful management of the outbreak (Kavanagh, 2020), a quantitative analysis of the first wave failed to identify any association between pandemic death rate and severity of democratic infringement (Maerz et al., 2020). Instead, policies that relied primarily on public trust accompanied by democratic accountability have been associated with the most positive pandemic outcomes (Grogan, 2020). The debate about how power should be (re-)distributed between governments and the public is far from resolved, and can be expected to gather intensity once the pandemic has been brought under control. This tension between collective action and government directives is also central to the debate surrounding sustainability and climate mitigation (Fischer et al., 2011), suggesting that it is a cross-cutting dimension that affects multiple debates about the future.

Our studies captured those two prominent dimensions of debate by instantiating them as independent variables. We presented people with four future scenarios that differed along those two dimensions: the first dimension (called orientation) captured the progressive (build back better) vs. return to normal dichotomy. The second dimension (called distribution of power) differentiated between two future roles for government. In the strong government scenarios, democratic governance is curtailed and most power rests with the government. In the individual autonomy scenarios, by contrast, authority was returned to the individual and grassroots organizations whereas government assumed a limited role. Figure 1 summarizes the scenarios (which differ between experiments and are reported verbatim in the online supplement) along these two orthogonal dimensions. A similar classification of possible futures was discussed in the media during the first wave of the pandemic (Mair, 2020; Yong, 2020), reflecting the broader political choices discussed over a longer time scale before the pandemic in the academic literature.

Our research questions were: (1) Do people have a preference for a return to normal vs. a more progressive future post-COVID? (2) do they prefer a future characterized by strong government or individual autonomy? And (3) do their future preferences align 


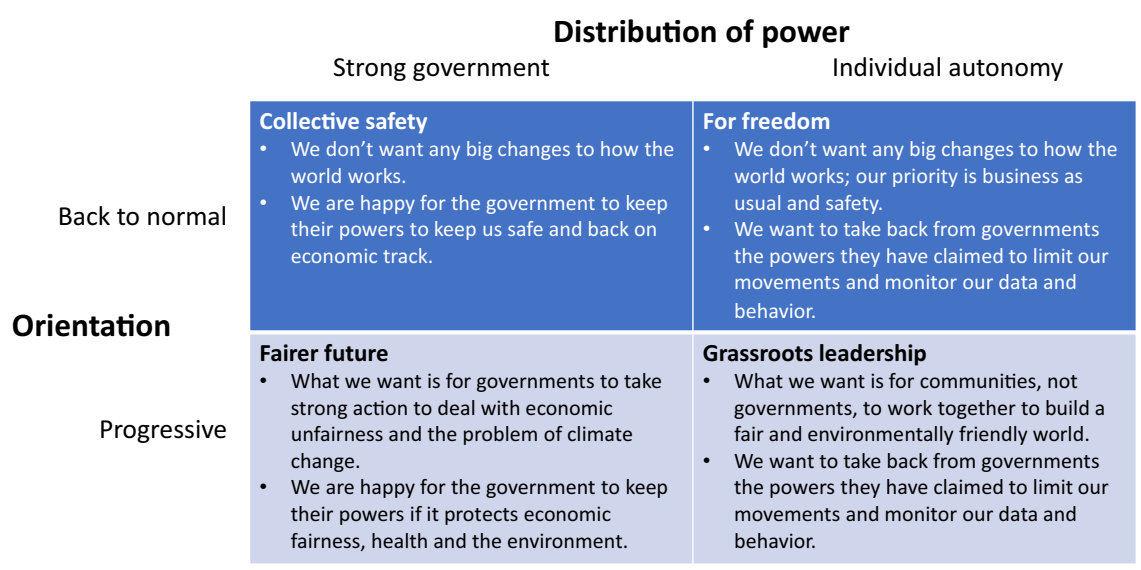

Fig. 1 Brief summary of the four scenarios used in the present experiments, grouped by the two dimensions (experimental variables) explored in the study. We designed each of these scenarios as having desirable aspects and being driven by good intentions, rather than juxtaposing scenarios that clearly differed with respect to intent and overall benefit. Any differences observed between scenarios should therefore reflect their deep structure instantiated by the experimental variables rather than emotional valence and overall attractiveness. Verbatim scenarios from both experiments are available in the online supplement.

with their expectations and the preferences they perceive others to have? To answer those questions, we performed two experiments about a year apart during different stages of the pandemic (May-July 2020 vs. July 2021). In the first experiment, participants evaluated all scenarios in succession, whereas in the second experiment participants were presented with one of the scenarios chosen at random. In both experiments, after each scenario, people first expressed their personal preference. They next rated the likelihood of the scenario coming to pass. The final evaluation question probed how much they thought other people would like the scenario. Probing of others' presumed attitudes is important because it can reveal gaps between people's own attitudes and their presumption about others' attitudes that can be politically consequential. It has long been known that people generally overestimate the prevalence of their own opinions (Holmes, 1968; Ross et al., 1977), a phenomenon known as the false-consensus effect (Mullen et al., 1985). On that basis, one would expect people's own preferences for the future to be reflected in their perceived preferences of others. There are, however, exceptions to this general pattern that can arise when a minority opinion is given disproportionate prominence in public debate and by the media, in which case the actual majority may think that their opinion is in the minority, a phenomenon known as pluralistic ignorance (Shamir \& Shamir, 1997; Todorov \& Mandisodza, 2004). The political implications of pluralistic ignorance can be profound. For example, after the terrorist attacks of $9 / 11$ the overwhelming majority of Americans (around 75\%) preferred a multilateral approach to combating terrorism. However, this majority thought that their view was only shared by half the population (Todorov \& Mandisodza, 2004), thus arguably rendering them more aqcuiescent to the unilateral approach pursued by the Bush administration with minority support of around $25 \%$. In the present context, testing for possible pluralistic ignorance is particularly relevant for three reasons: First, perceived social consensus is an important determinant of climate-change attitudes (Goldberg et al., 2020; Lewandowsky et al., 2019). Second, the social consensus is often misperceived, and pluralistic ignorance in people who accept the reality of human-caused climate change has been observed repeatedly (Leviston et al., 2013; Mildenberger \& Tingley, 2019; Pearson et al., 2018). Third, people who are concerned about climate change are reluctant to express those opinions if they (falsely) believe that others do not share this concern (Geiger and Swim, 2016). In light of the prominence of climate change and related issues in the debate about post-COVID futures, probing of others' presumed attitudes therefore appeared particularly important.

In addition, given that personal values and norms have been identified as drivers of prosocial responses to COVID-19 (Bouman et al., 2021), we anticipated that people's core moral values might predict their preferences. In the first experiment, we therefore employed the Moral Foundations Questionnaire (MFQ; Graham et al., 2020) to measure participants' values in our first (US) sample. The MFQ measures a person's values along dimensions of harm/care, fairness/reciprocity, ingroup/loyalty, authority/ respect, and purity/sanctity. Although we did not have any specific hypotheses, we expected that fairness might predict preferences along the orientation factor, and authority might predict preferences along the distribution of power factor. Contray to expectation, the MFQ did not play a major role in determining people's responses. It was therefore dropped from all subsequent samples. Experiment 2 instead measured people's political leaning along a "left-right" continuum as a potential moderator.

Standard demographics (age, gender, education, and income) were included as potential covariates in Experiment 1. It is known that climate-change denial is stratified by income and education (Bohr, 2014; Hamilton, 2011), as well as gender (Krange et al., 2018; McCright, 2010). Men tend to be less concerned about climate change than women (McCright, 2010), and increasing age is also associated with decreasing concern (Hamilton, 2011).

Finally, respondents were also given the opportunity to express their feelings about the pandemic and possible futures in openended questions in Experiment 1. These responses were subjected to an inductive qualitative analysis that provided an in-depth exploration of the quantitative results. Qualitative analyses have yielded valuable insights into how people conceptualize policies and governance approaches in related domains, such as sustainability and climate change (Fischer et al., 2011).

\section{Experiment 1 \\ Methods}

Design and scenarios. The experiment involved two nearly identical instruments administered to representative U.S. and U.K. samples. The American sample was tested in early May 2020, at a time when most U.S. States were still in lockdown, whereas the British sample was tested in early July 2020, at which time the U.K. was emerging from its first lockdown. 
Because of the difference in timing, we present the results from the two samples separately.

The two within-subjects experimental variables defined the scenarios presented to participants. The first variable, which we call orientation, referred to the basic thrust of the future scenario. The orientation was either back to normal or progressive. The second variable, which we call distribution of power, referred to the role of government in the future. It either stipulated strong government or individual autonomy. The orthogonal combination of these two variables yielded the four scenarios shown in Fig. 1.

1. For freedom scenario (back to normal and individual autonomy) effectively accentuated the status quo before the pandemic; namely small government, individual freedom, and business as usual.

2. Grassroots leadership scenario (progressive and individual autonomy) sketched a future driven by communities, not governments, working together to build a fair and environmentally friendly world.

3. Collective safety scenario (back to normal and strong government) also accentuated the status quo before the pandemic but expected that the government would keep its newly-acquired powers to keep people and the economy safe.

4. Fairer future scenario (progressive and strong government) also accepted that governments retain their power but expected them to take strong action to deal with economic unfairness and climate change.

The online supplement contains verbatim copies of the scenarios.

Scenario calibration. Because our research questions were formulated at the level of experimental variables rather than pertaining to the specific wording of the scenarios, we conducted a separate study to verify that people perceived our scenarios along the dimensions we intended to manipulate.

We recruited 404 participants (mean age 40.65, range 18-79; 240 male, 160 female, 3 non-binary, and 1 withheld response) from the CloudResearch Approved Participants pool of MTurk users. CloudResearch (https://www.cloudresearch.com/) vets MTurk workers for reliability before they enter the Approved Participants pool. The pool is demographically diverse and participants are similar to other MTurk workers. All participants were U.S. residents, had an approval rating of $98 \%$ or better, and had participated in at least 5000 previous tasks (HITs) on MTurk. Participants were paid $\$ .75$ for completion of the survey, which took $\sim 3.5 \mathrm{~min}(203.30 \mathrm{~s}$ ) on average (median $147.50 \mathrm{~s}$ ).

Each participant was presented with a single scenario, chosen at random. After a delay of $30 \mathrm{~s}$, participants responded to two items querying the nature of the scenario. The first item queried orientation: Futures after COVID are often classified along a continuum from return to normal to building back better. Where do you place this scenario along that continuum? The response scale consisted of 10 horizontally arranged radio buttons with end points labeled return to normal and building back better. The second item queried distribution of power: Futures after COVID are often classified along a continuum from returning/giving power to the people to government retains/gets more power. Where do you place this scenario along that continuum? End points on this 10-point response scale were labeled people power and government power. Participants were then asked if they had put in a reasonable effort and whether their data should be used for analysis (with response options Yes, I put in reasonable effort; Maybe, I was a little distracted; or No, I wasn't paying much attention), before being debriefed. No participants indicated that they were not paying attention.

The top panel in Fig. 2 shows the results, with responses to the two items plotted along the abscissa (orientation) and ordinate (distribution of power), respectively. Although there is some variability between participants, it is clear that people perceive the scenarios as intended along a $2 \times 2$ factorial structure. The mean responses along the orientation dimension are identical for both back to normal scenarios and for both build back better scenarios, with the two types differing as expected along the orientation dimension. Similarly, responses along the distribution of power dimension were principally determined by whether the scenario was highlighting people or government power, although the two individual-autonomy (people power) scenarios differed slightly from each other (with the confidence intervals nonetheless overlapping). We therefore conclude that the four scenarios instantiated the two experimental variables as intended.

Participants for main study. Representative samples of participants in the US and UK were recruited via the Prolific platform (https://www.prolific.co/). Prolific has been shown to yield responses of higher quality and samples that are more diverse compared to rival panel services (Peer, Brandimarte, Samat, \& Acquisti, 2017). Prolific stratifies representative samples across three demographic variables: Age (five brackets; 18-27, 28-37, 38-47, 48-57, and 58 and above), gender (male and female), and ethnicity (five groups; White, Mixed, Asian, Black, and Other). Prolific uses census data from the US Census Bureau or the UK Office of National Statistics to divide the sample into 50 subgroups $(5 \times 2 \times 5)$ with the same proportions as the national population, which are then filled by invitation to the overall panel. Table S1 compares the sample statistics on the stratification variables to the population demographics. The U.S. sample comprised 277 participants, who were paid GBP1.88 ( \$2.40) each for the 15-min survey. The average age was 46 (range 18 to 79 ; $\mathrm{SD}=16.20)$. The U.K. sample comprised 300 participants who were paid GBP1.75 each for the slightly shorter (14-min) survey. The average age was 45.20 (range 19 to 85 ; $\mathrm{SD}=15.92$ ). Table S2 summarizes the remaining demographics of both samples and provides a comparison to the national populations for the stratification variables.

Procedure. Upon providing informed consent, participants first responded to demographic items (age, gender, English proficiency, employment status, level of education, and annual income). Participants in the U.S. sample then completed the 20item version of the Moral Foundations Questionnaire (MFQ; Graham et al., 2020). The MFQ is split into five subscales (harm, fairness, ingroup, authority, purity). MFQ items used a 6-point scale from $1=$ Strongly disagree to $6=$ Strongly agree.

Participants then proceeded to the main part of the experiment, which consisted of presentation of the four future scenarios, in a new random order for each participant. Each scenario was followed by three questions: (1) How much do you want this scenario to come true? (Short label own want in remainder of analysis); (2) How likely is it that this scenario will come true? (likelihood); (3) How much do you think other people in the U.S./U.K. would like this scenario to come true? (others want). Each question was answered on an 11-point scale with end points $1=$ Not at all and $11=$ Very much.

The scenarios were followed by four open-ended qualitative items. The items queried (1) What do you most miss from life before the pandemic?; (2) What are you happy to have lost from life before the pandemic?; (3) What is different now-about your life, about society, about the world - that you would like to stay different after the pandemic?; and (4) What would you like to be 

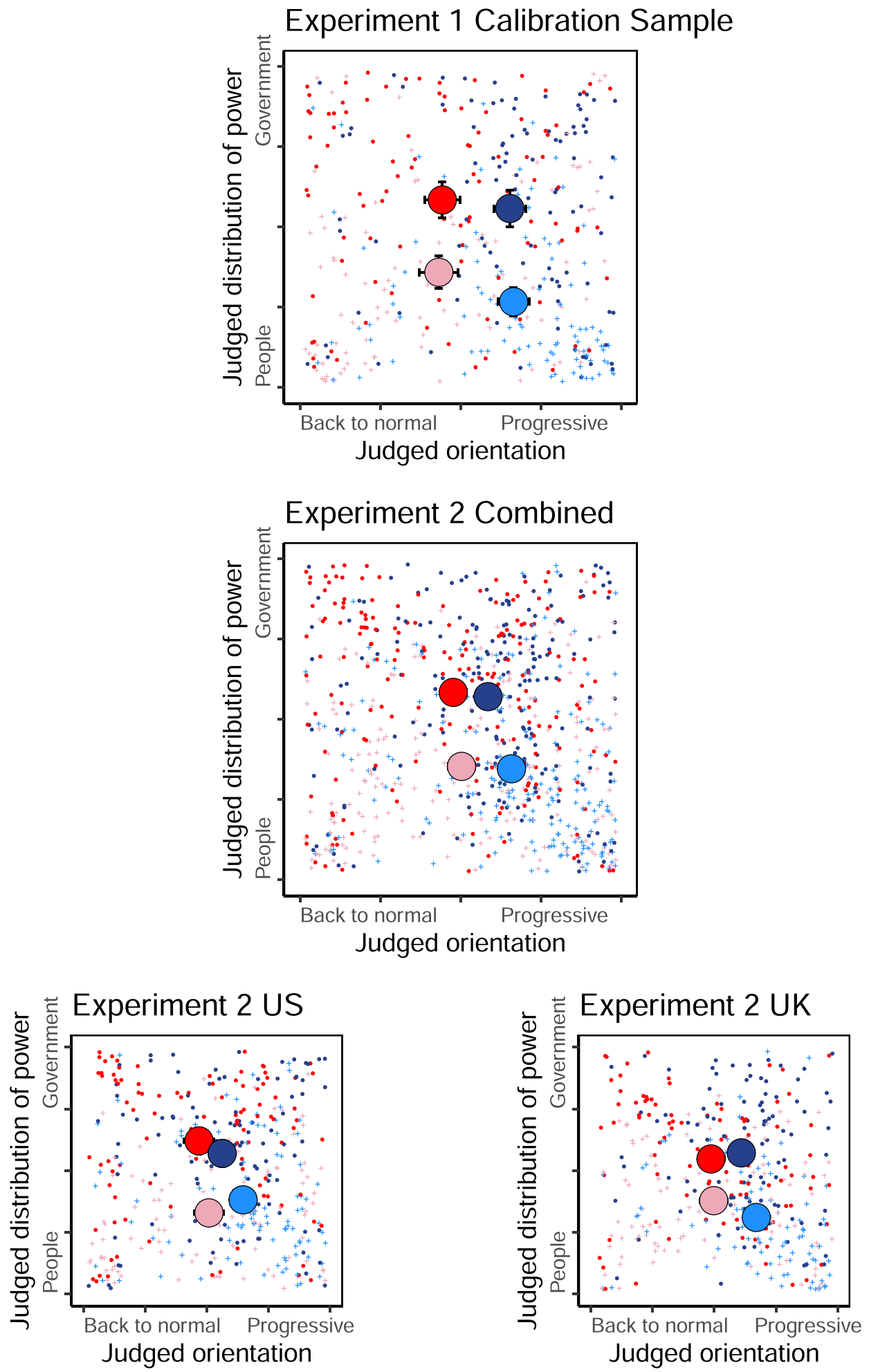

Scenario: Collective
safety Fairer future

For freedom

Grassroots

leadership

Fig. 2 Results of scenario calibration when participants were asked to rate each scenario along the dimension instantiated by each experimental variable. The top panel reports the study embedded in Experiment 1, and the remaining panels show the calibration responses from Experiment 2 for both samples combined (center panel) and the individual samples (bottom row of panels). In each panel, large plotting symbols represent means along the two dimensions and error bars represent $95 \%$ confidence intervals. Individual responses are shown by small symbols with jitter to avoid overprinting. 
different-about your life, about society, about the world-after the pandemic compared to before?

The qualitative items were followed by a final query that asked participants if they had put in a reasonable effort and whether their data should be used for analysis (with response options Yes, I put in reasonable effort; Maybe, I was a little distracted; or No, I really wasn't paying any attention). Respondents who chose the last option would have been excluded from analysis (but none did).

Analysis. The quantitative analysis of responses to the four possible future scenarios relied on linear mixed-effects models fitted by the $\mathrm{R}$ function lmer, which is part of the lme 4 package (Bates et al., 2015). The principal model included both experimental variables and their interaction as fixed effects, and also added the main effects as random variables. A separate model was fit to each of the three questions (own want, likelihood, others want) for each sample. This model roughly corresponds to a within-subjects analysis of variance and yields comparable results (Brauer et al., \& Curtin, 2018). We call this the simple model. By default, Imer returns unstandarized coefficients, but we also report standardized values for the fixed effects in the simple models.

In addition, for each question and sample we also created a model that included the remaining variables (demographics and responses to the MFQ when present) as potential covariates. These models are called the complex models. In all instances, the simple model was preferable to the complex model when the comparison was corrected for complexity using BIC (Schwarz, 1978). Although this opens the door to the conclusion that the inclusion of covariates is unnecessary, the complex model was favored by a significant likelihood test in many instances. Because the complex models did not yield any striking or theoretically interesting insights, they are reported in the online supplement only.

We also report a power analysis for the fixed effects using the $\operatorname{sim} R$ package (Green and MacLeod, 2019). Retrospective power analysis (i.e., estimating power based on the effect size estimated in the same data) is problematic and discouraged because it can yield misleading results (Gelman and Carlin, 2014). The simR package circumvents this problem through a simulation approach to estimate power for given effect sizes. We report the effect sizes (expressed as unstandardized regression weights) for each fixed effect that would have been detected with a power of $80 \%$ and $90 \%$ (by incrementing effects by .02 from 0 until mean simulated power exceeded the target). The power analysis is reported in supplementary Tables S4 and S5.

The qualitative part of the investigation used an inductive thematic analysis of the responses provided to the four openended questions. The analysis allowed us to understand the reasons that people provided for their responses to the scenarios. The qualitative responses also allowed us to identify different groups of respondents in our samples, which were then explored further in another exploratory quantitative analysis.

We analyzed responses to each of the open-ended questions with Nvivo 12 (https://www.qsrinternational.com/nvivo-qualitative-dataanalysis-software/home), which produced the word clouds and the word tree reported below. We also hand-coded the analysis, using Grounded Theory (Strauss \& Corbin, 1994). That is, categories for the responses were first inductively created from analysis of a subset of responses. These categories were then systematically applied to the full sample, before being used to generate theoretical categorizations to support interpretation of the results.

Each answer could be coded multiple times reflecting different elements of the response. For example, a response I miss my family, going to the cinema and feeling relaxed in public would be given three codes. This analysis was used to assist in interpreting the word clouds. Because the open-ended responses were strikingly similar across the samples, we present the results together. We did not analyze the qualitative data for demographic differences.

Results. Figure 3 shows responses to the three main questions for both samples.

What did people want to happen in the future? People in both countries strongly preferred the progressive scenarios to the back-tonormal scenarios (top row in Fig. 3). People also slightly preferred individual autonomy to strong government interventions. For the U.S. sample, there were significant effects of orientation, $\hat{\beta}=-1.27$, $95 \%$ CI $[-1.45,-1.10], t(399.02)=-14.22, p<0.001$ (standardized coefficient -0.39 ), and distribution of power, $\hat{\beta}=0.37,95 \% \mathrm{CI}$ $[0.20,0.55], t(396.80)=4.17, p<0.001$ (standardized coefficient 0.11 ), but no interaction between the two factors, $\hat{\beta}=0.09,95 \% \mathrm{CI}$ $[-0.05,0.22], t(265.69)=1.28, p=0.201$ (standardized coefficient 0.03). For the U.K., there was also a significant effect of orientation, $\hat{\beta}=-1.16,95 \%$ CI $[-1.33,-0.99], t(455.82)=-13.31, p<0.001$ (standardized coefficient -0.36), but unlike in the U.S. sample, there was no main effect of distribution of power, $\hat{\beta}=-0.05,95 \% \mathrm{CI}$ $[-0.22,0.11], t(437.45)=-0.64, p=0.525$ (standardized coefficient $-0.02)$. Instead, there was an interaction, $\hat{\beta}=0.30,95 \%$ CI $[0.17$, $0.44], t(276.71)=4.52, p<0.001 \quad$ (standardized coefficient 0.10 ), indicating that while British participants, like the Americans, preferred greater individual autonomy for the back-to-normal scenario, their preference was reversed for the progressive scenario. That is, if things were to go back to normal, then British respondents did not want strong government, but if things were to change towards a progressive future, then stronger government was preferred.

One advantage of the within-subject design was that it permitted us to identify a winning scenario among the four presented for each participant by picking the highest preference rating (with ties broken at random). The distribution of winners mirrorred the results in Fig. 3. The majority of U.S. respondents favored the Fairer Future $(N=108 ; 39 \%)$ and Grassroots Leadership $(N=111$; $40.10 \%$ ) scenarios, for a combined total of $N=219$ for the progressive scenarios. The return to normal scenarios were preferred by only 58 participants, with the Collective Safety $(N=19 ; 6.90 \%)$ being least preferred compared to the For Freedom scenario $(N=39 ; 14.10 \%)$. The pattern was similar for UK respondents, who also favored the Fairer Future $(N=114$; $38 \%)$ and Grassroots Leadership $(N=109$; 36.30\%) scenarios (combined $N=223$ for progressive futures). The Collective Safety $(N=30 ; 10 \%)$ and For Freedom $(N=47 ; 15.70 \%)$ scenarios again were only preferred by 77 participants overall.

The within-subject design also gave rise to a potential disadvantage. Given that people considered multiple scenarios, it is possible that the results are affected by carry-over effects between successive responses (although the randomization of order should have mitigated the impact of such effects). To rule out that carryover effects contributed unduly to the observed pattern, the scenario calibration study, in which (U.S. based) participants only responded to a single scenario, also included the same own want item that was used in the main study. A $2 \times 2$ between-subjects ANOVA conducted on those responses revealed qualitatively identical results to the main study, with a main effect of distribution of power, $F(1,400)=17.58, \quad \mathrm{MSE}=10.19, \quad p<0.001, \hat{\eta}_{G}^{2}=0.042$, a main effect of orientation, $F(1,400)=44.37, \quad M S E=10.19, p<0.001$, $\hat{\eta}_{G}^{2}=0.100$, and a marginally significant interaction between both variables, $F(1,400)=3.92, \quad \mathrm{MSE}=10.19, \quad p=0.048, \quad \hat{\eta}_{G}^{2}=0.010$. Paralleling Fig. 3, people strongly preferred a progressive future $(M=6.52)$ to a return to normal $(M=4.41)$, and they preferred a future in which power rested with the people $(M=6.13)$ rather than 
Own want U.S.

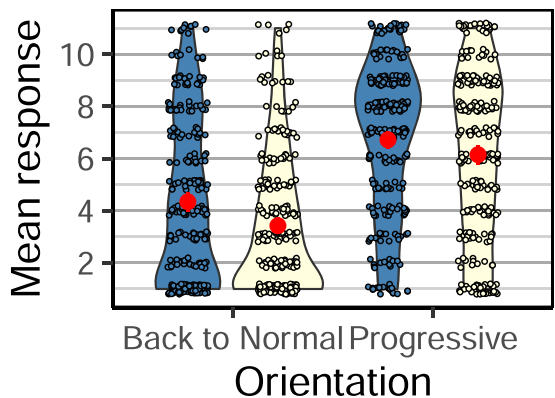

Likelihood U.S.

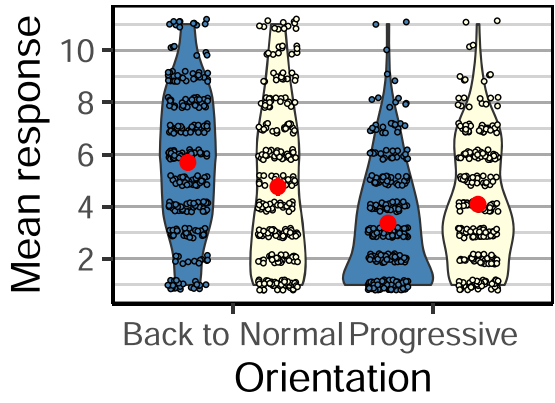

Others want U.S.

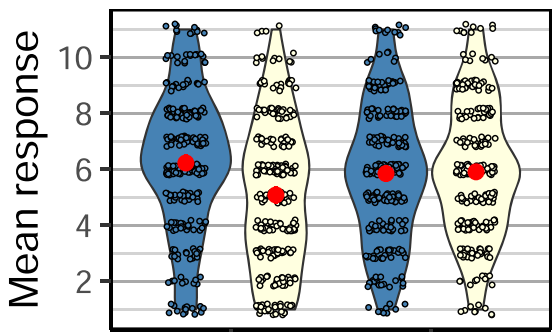

Back to Normal Progressive

Orientation
Own want U.K.

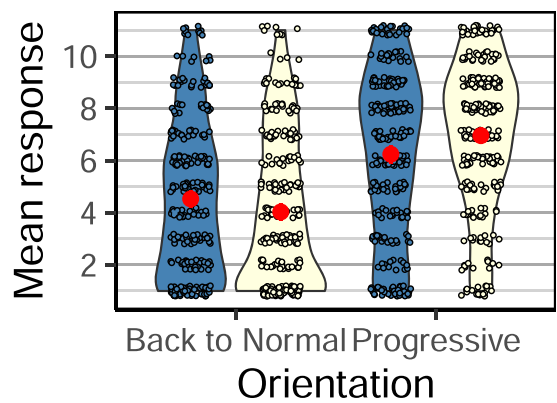

Likelihood U.K.

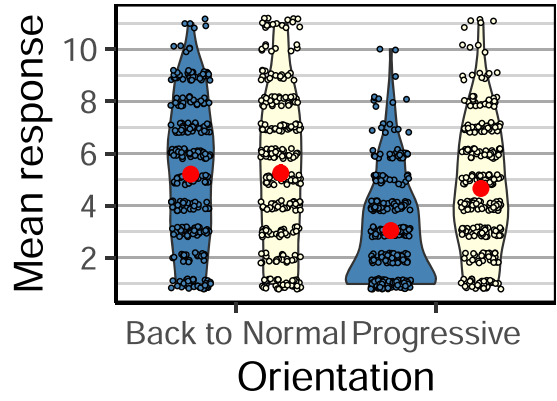

Others want U.K.

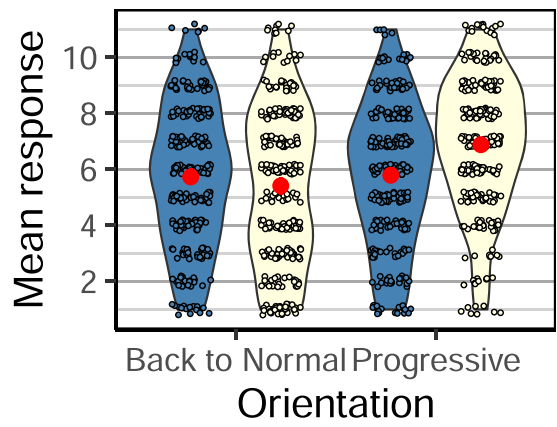

\section{Distribution of power $\$$ Individual autonomy $\$$ Strong government}

Fig. 3 Responses to three main questions in Experiment 1. Panels on the left show responses from the US, and panels on the right from the UK. The top row reports people's own preferences, the center row reports likelihood, and the bottom row perceptions of what others want. In each panel, the red plotting symbols and error bars represent means and 95\% confidence intervals. Data are jittered to avoid overprinting. See text for details.

the government $(M=4.79)$. (The effect size of the interaction was considered too small to warrant detailed exploration). This betweensubjects replication confirms that our main result was not unduly affected by carry-over effects or other complications arising from a within-subjects design.

What did people think would happen? In striking contrast to their own preferences, participants expected that the future would involve a return to normal rather than their desired progressive and more sustainable options (center row Fig. 3). For the U.S. sample, there was a strong main effect of orientation, $\hat{\beta}=0.75,95 \%$ CI $[0.58$, 0.92 ], $t(421.24)=8.70, p<0.001$ (standardized coefficient 0.28 ), no effect of distribution of power, $\hat{\beta}=0.05,95 \%$ CI $[-0.08,0.18]$, $t(312.85)=0.77, p=0.441$ (standardized coefficient 0.02 ), and an interaction between the two factors, $\hat{\beta}=0.41,95 \%$ CI $[0.30,0.53]$, $t(302.28)=6.96, p<0.001$ (standardized coefficient 0.15 ). For the U.K. sample, there was also a strong main effect for orientation, $\hat{\beta}=0.69,95 \%$ CI $[0.54,0.84], t(368.15)=9.04, p<0.001$ (standardized coefficient 0.26 ), and an interaction, $\hat{\beta}=0.39,95 \%$ CI $[0.29$, 0.49 ], $t(341.33)=7.58, p<0.001$ (standardized coefficient 0.15 ). Unlike in the U.S. sample, the main effect of distribution of power, $\hat{\beta}=-0.42,95 \%$ CI $[-0.55,-0.28], t(324.40)=-6.02, p<0.001$ (standardized coefficient -0.15), was also significant. In both samples, the interactions arose because participants judged the progressive scenario with individual autonomy to be particularly unlikely-or, equivalently, to the extent that a progressive future might occur, it was expected to come with strong government. At the same time, people judged individual autonomy to be as likely (U.K.) or more likely (U.S.) than strong government for the return to normal scenarios. 
What did people think others wanted from the future?. People's perceptions of what others want for the future (bottom row Fig. 3) differed considerably from their own preferences. For the U.S. sample, there was a significant effect of distribution of power, $\hat{\beta}=0.27,95 \%$ CI $[0.15,0.39], t(305.51)=4.42, p<0.001$ (standardized coefficient 0.11 ), no effect of orientation, $\hat{\beta}=-0.11$, $95 \%$ CI $[-0.28,0.06], t(450.47)=-1.30, p=0.195$ (standardized coefficient -0.04$)$, and an interaction between the two factors, $\hat{\beta}=0.30,95 \%$ CI $[0.19,0.42], t(300.73)=5.20, p<0.001$ (standardized coefficient 0.12 ). People thought that others did not share their own overall preference for a progressive scenario, overestimating others' preference for a return to normal. People also believed that others were disinclined to return to normal under a strong government. For the U.K., the simple model identified significant effects of orientation, $\hat{\beta}=-0.38$, 95\% CI $[-0.53,-0.23], t(411.28)=-4.97, p<0.001$ (standardized coefficient -0.15$)$, distribution of power, $\hat{\beta}=-0.19$, 95\% CI $[-0.33,-0.05], t(369.89)=-2.74, p=0.006$ (standardized coefficient -0.07 ), and the interaction, $\hat{\beta}=0.35,95 \%$ CI $[0.23,0.47]$, $t(344.21)=5.65, p<0.001$ (standardized coefficient 0.13 ). Unlike for the U.S. sample, participants correctly judged that people overall preferred the progressive scenarios, although they again overestimated others' preference for a return to normal.

Anticipated disappointment. The online supplement also reports an analysis of anticipated disappointment, operationalized as the discrepancy between what people want (top panels Fig. 3) and what they expect to get (center row Fig. 3). In a nutshell, this analysis showed that greater age (and in the US sample: stronger in-group allegiance; in the UK: greater income) was associated with a lower expectation of being disappointed by the future world. (Details in Tables S9 and S10.)

Exploring people's views of the future. We next report the qualitative data. These data reveal people's specific hopes for the future and sense of loss through the pandemic at a greater level of granularity.

What do people miss from life before the pandemic? Fig. 4 (left) shows the word clouds of open-ended responses from both samples to the question what do you most miss from life before the pandemic. We see a combination of people, activities, freedoms, bodily experiences and states of mind. The most frequently mentioned things that people missed were: Interaction with family and friends $(N=131$ mentions in U.S. $/ N=142$ mentions in U.K.), going to bars and restaurants (78 U.S./80 U.K.), freedom from anxiety of illness or contagion (66 U.S./44 U.K.), going to movies and other cultural activites (festivals, museums) (51 U.S./43 U.K.), non-essential shopping, including window shopping and browsing (45 U.S./24 U.K.), as well as touch/physical presence (42 U.S./39 U.K.). This response provides an illustration:

I miss being able to go to the store. I miss visiting with my children and grandchildren. I miss not having to worry about what I'm touching or what the other person next to to me might be carrying. I miss going to a movie. I miss moving about in a crowd of people without being filled with anxiety. I miss touching people. I miss the touch from people. I miss going out for a meal in a nice relaxing atmosphere. I miss life.

Differences between the two samples relate to events when the surveys were administered. More British $(N=131)$ respondents missed freedom of movement than Americans $(N=77)$, likely because the U.K. survey was administered when it became clear that summer holidays would be canceled. Some British respondents $(N=42)$, but no Americans, reported missing the freedom from wearing a mask because mask wearing was introduced at the time in the U.K. but not the U.S.

What are people happy to lose from life before the pandemic? The most frequent single response to this was nothing $(N=63$ in U.S., and $N=64$ in U.K.). This is worth noting both for its potential approval of the pre-pandemic world but also for the fact that some people's experience of the pandemic was clearly extremely negative. The supplement reports a quantitative comparison of these respondents to the remaining participants who identified some things they were happy to lose. Unsurprisingly, people who wanted nothing to change preferred a return to normal more (and a progressive future less) than their counterparts but differed little on the other two scenario questions (Figs. S5 and S6). Analysis of demographics identified people who wanted no change as being older than the others (see supplement).

Among people who responded with something other than nothing, a sizeable group (59 U.S./65 U.K.) was pleased to have lost unwanted travel, commuting, and the assumption that work could only be done face to face. Others reported enjoying a break from stress, over-commitment and a busy life (52 U.S./58 U.K.). The following quotation gives a flavor:

The constant, constant pressure and anxiety. I was alwaysfrom the time I woke up to the time I went to bedcalculating what needed to be done next, how quickly it needed to be done, and how many different things can I do at the same time to make sure it ALL gets done? After this, I hope I never go back to that. I want to forget that ever was my life.

Perhaps the most interesting response is from people who reported a change in mindset during the pandemic that they welcomed-both in themselves and in others (29 U.S./33 U.K.):

This forced everyone to slow down and appreciate the smaller things in life. I won't miss overlooking all of the little things-I now have more appreciation for all the things we considered standard in life pre-covid.

A subset of both groups were also pleased to have lost pollution (32 U.S./48 U.K.) and traffic noise (9 U.S./7 U.K.); as well as crowds (19 U.S./ 34 U.K.) and intimate physical interactions such as hugs (21 U.S./11 U.K.).

What do respondents want from the future? Future wants cluster, again, around human relationships and the organization of working life (Fig. 4, right). Working from home (54 U.S./60 U.K.) and a slower pace of life (39 U.S./40 U.K.) were cited most often as desirable pandemic-induced changes. Numerous responses cited changed social relationships, such as wanting to keep a sense of collective friendliness (32 U.S./44 U.K.), wanting to keep greater care for other people (25 U.S./28 U.K.) and the environment (39 U.S./56 U.K.). The flipside to these desires for sociality and care was a desire amongst some respondents to maintain social distancing and keep crowds down (36 U.S./26 U.K.). One response that featured more prominently in the U.K. than the U.S. was to retain a greater appreciation of essential workers (5 U.S./22 U.K.). Only a minority wanted to keep nothing from their experiences of the pandemic (31 U.S./16 U.K.; these participants were included in the no change group in the analysis in Figs. S5 and S6).

Many respondents wanted a less individualistic and more caring future (67 U.S./72 U.K.) or changed economic values 

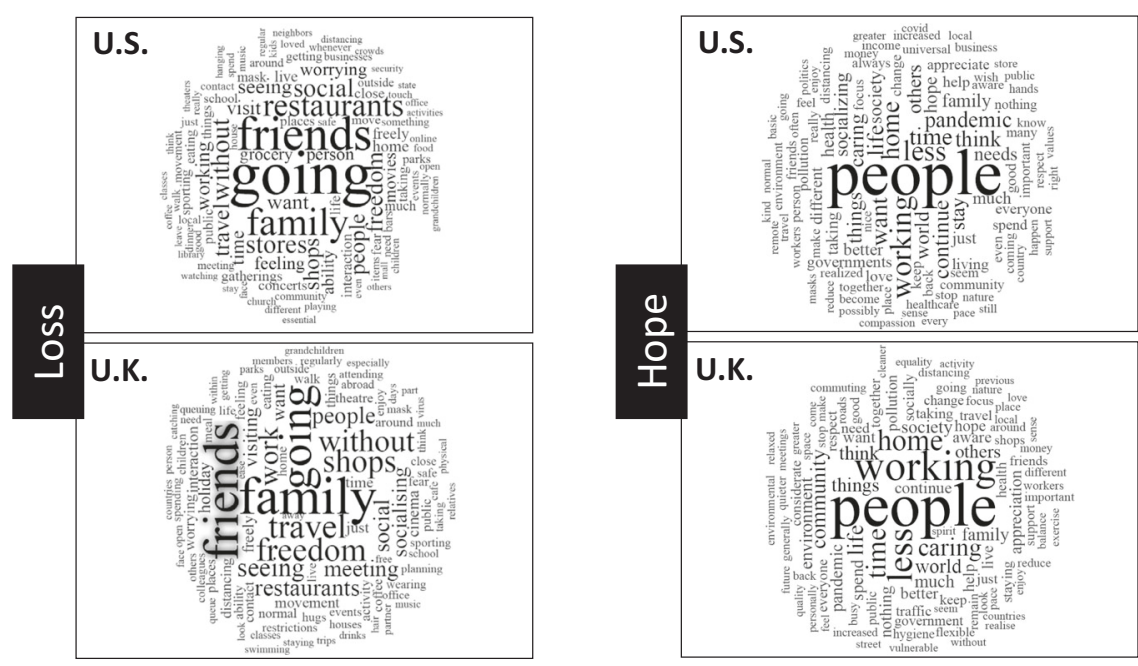

Fig. 4 Experiment 1: Word clouds computed by Nvivo 12 of open-ended responses to three questions for both samples. Left panels: responses to the question What do you most miss from life before the pandemic? Right panels: responses to the questions What is different now-about your life, about society, about the world-that you would like to stay different after the pandemic? and What would you like to be different-about your life, about society, about the world-after the pandemic compared to before? (right). All stemmed words over four letters long were included, except for a limited list of stop words and words that replicate the language of the question (e.g., "miss" for the first question was removed from these responses). See text for details.

(46 U.S./31 U.K.). We also see some differences emerging between the two samples: Only 19 in the U.S. named remote working as a priority for a future world compared with 60 in the U.K.; only 35 in the U.S. suggested they would want to use their time differently compared with 61 in the U.K. In contrast, desires for a better healthcare system and access were higher in the U.S. (33) compared with the U.K. (13). This difference likely reflects Britons' satisfaction with their National Health Service.

Desires for new political practices were visible across both surveys but took a slightly different flavor. While in the U.K. the focus was on addressing racism (the survey was administered after the rise of the Black Lives Matter movement), in the U.S. there were 8 respondents who wanted a change in political leadership (We also need a new president who isn't a venal, mentally ill liar), 22 argued for more transparent, evidence based, competent politics, 9 argued for the need for respect for science and for good education, and 18 argued for more tolerance and less partisan politics:

I would like to see us come together more when bad things happen. I want us to always circle the wagons when it comes to personal, societal, and worldly issues confronting us. Let go of the partisanship! (U.S. respondent).

I would like to see a healthier environment where people are kinder to each other, more generous, and caring. Less of the it's about me society. The individual matters of course, but we need to care for each other, and this planet (U.K. respondent).

A striking aspect of all responses is the emphasis on people (Fig. 4, right). To explore this further, we rank-ordered words by frequency collapsing across samples (Fig. 5A). The word people is not only most frequent, reflecting the central importance of human interaction, but it is also far more frequent than its closest neighbor. If we further unpick the use of people, it turns out to be primarily associated with the desire for different behavior by other people. Many responses followed the structure I would like people/ I would like for people/ I wish people ... followed by statements such as: to continue to be less impatient, continue to drive less, be more friendly, really reevaluate themselves, take a good look at their life, remain as considerate ... (Fig. 5B; supplement contains the complete word tree).

\section{Experiment 2 \\ Methods}

Design and scenarios. The second experiment again involved representative U.S. and U.K. samples that were tested using the same general procedure in late July and early August 2021, more than a year after the first study. At that time both countries had fully vaccinated roughly half their population, and lockdown restraints were largely lifted in both countries.

The second experiment was similar to the first one, with the following important differences: First, the two experimental variables, orientation and distribution of power, were manipulated between participants, and each participant only responded to a single scenario. This traded off the ability in the withinsubjects design to identify people's most preferred scenario and to examine anticipated disappointment, against preventing potential carry-over or sequence effects when people respond to multiple scenarios. Second, although the scenarios were instantiating the same experimental design that was used in Experiment 1 (Fig. 1), the scenarios were revised by building them from a common underlying syntactic structure. The structure operationalized the two experimental variables and sought to eliminate any other differences between scenarios. This traded off narrative flow against greater experimental control. The online supplement contains verbatim copies of the scenarios. Third, we removed most of the items testing potential covariates because they did not reveal particularly interesting patterns in the first experiment. Instead, we added a single item that asked participants to indicate their political leaning along a left-right continuum. Given the growing political polarization around issues such as climate change and COVID-19 in the US (and to a lesser extent in the UK), inclusion of a political measure as a potential moderator of the effects seemed advisable. Experiment 2 did not include any qualitative items. 


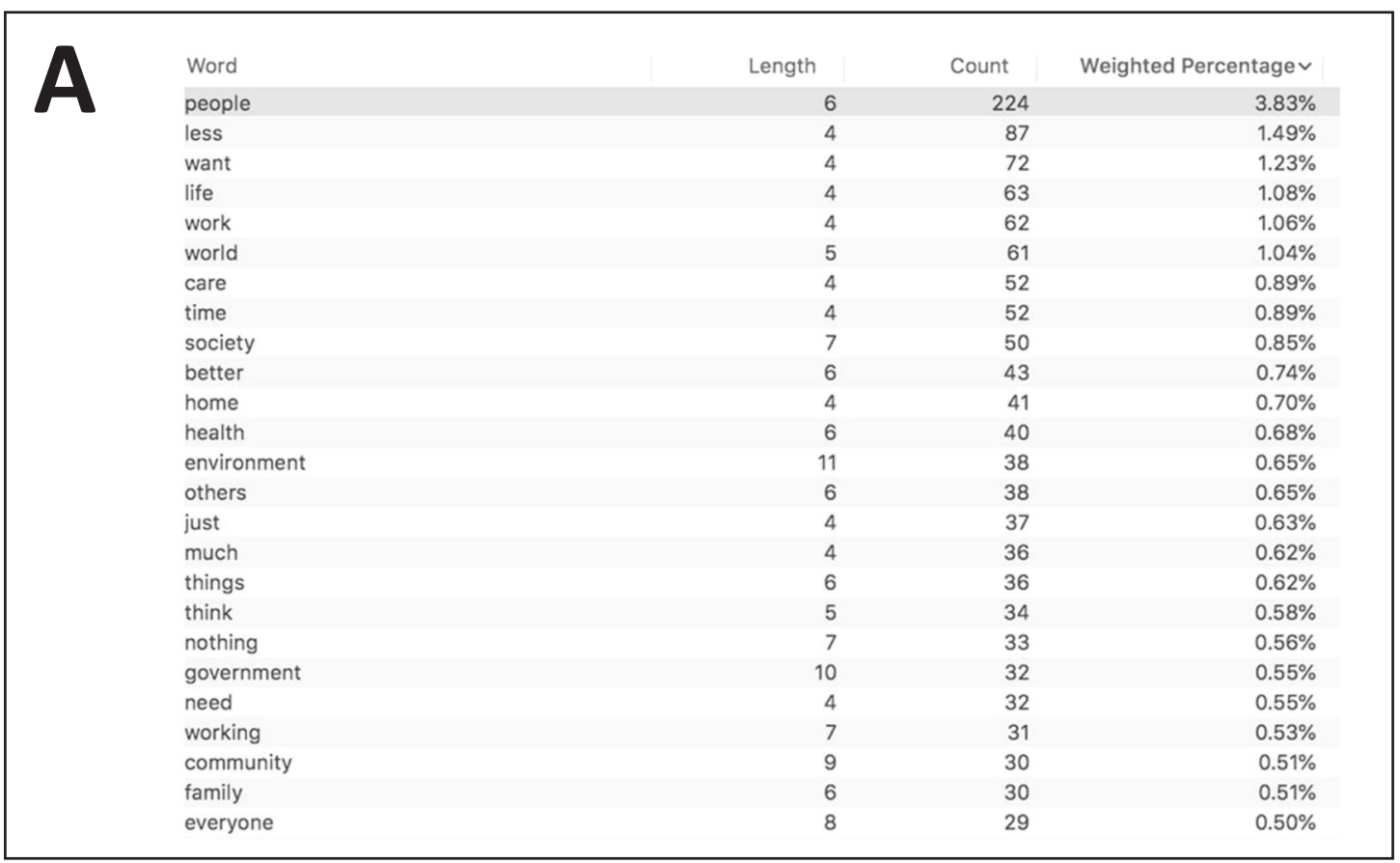

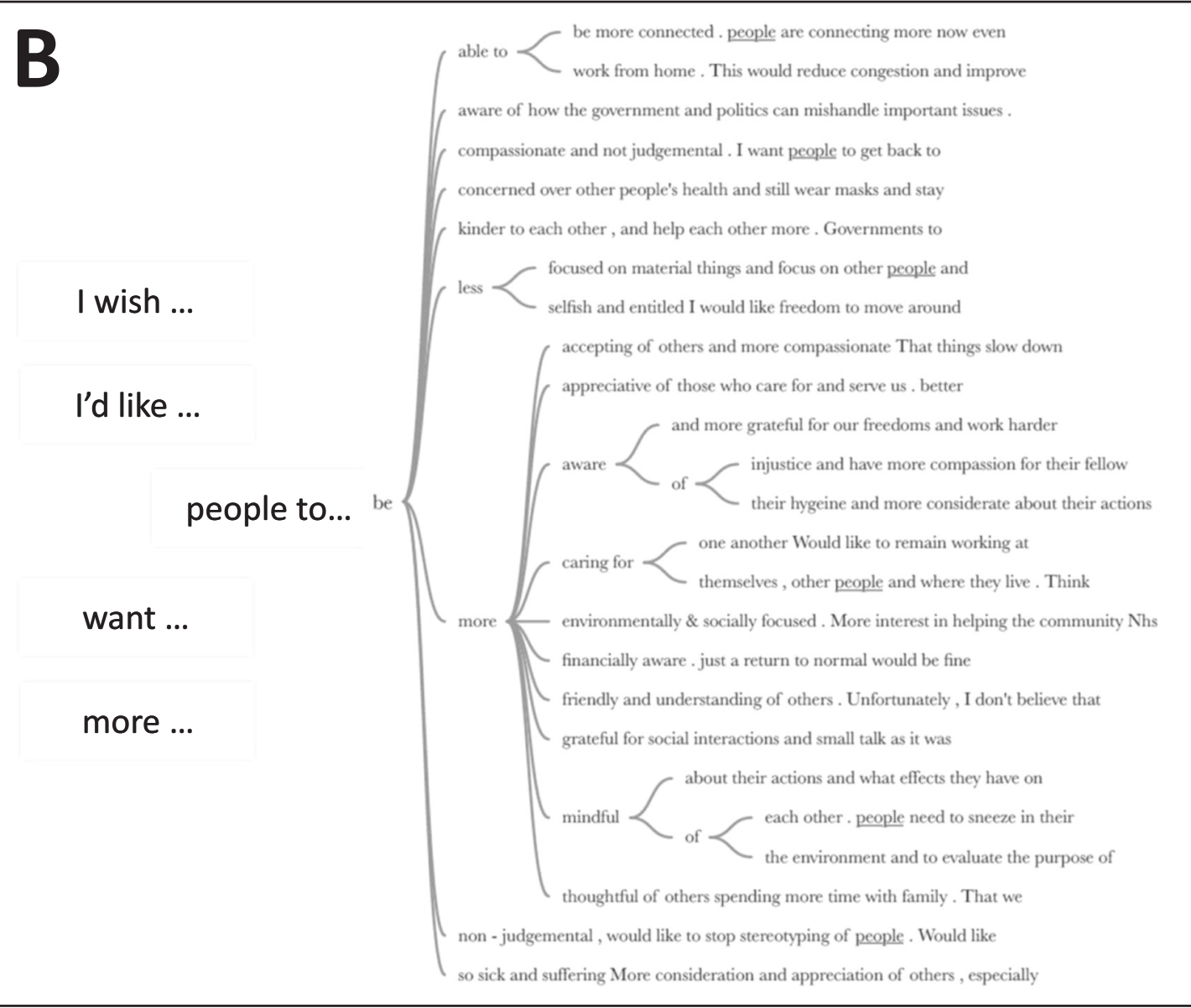

Fig. 5 Experiment 1: Responses across both samples to the final open-ended question (what would you like to be different-about your life, about society, about the world-after the pandemic compared to before?). A 25 most frequent words in responses. B Partial word tree summarizing responses across both samples. See text for details. 
Participants. Participants were recruited from the same source (Prolific representative sample) as in Experiment 1. Participants were paid GBP 0.60 ( \$.75) each for the 5-min survey. The U.S. sample comprised 401 participants, whose average age was 44.80 (range 18 to $80 ; \mathrm{SD}=15.71$ ). The U.K. sample comprised 398 participants with an average age of 45.10 (range 18 to 88; $\mathrm{SD}=15.73$ ). Table S3 summarizes the demographics of both samples and provides a comparison to the national populations for the stratification variables.

Figure S1 provides an overview of the political leanings of our samples and includes a comparison to two previous large surveys (national election studies) that used the same item. Although the Prolific samples are designed to be representative with respect to demographics (age, gender, and ethnicity), the provider does not ensure representativeness with respect to political leanings. It is therefore unsurprising that the samples differed from the comparison distributions, with left-wing responses generally being oversampled and right-wing responses being undersampled. The departure from the population distribution was particularly pronounced for the U.S. sample. We correct for these sampling biases in a further analysis, reported in the supplement, that reweighted all observations based on the estimates of the population distribution from the national election studies. The results of the reweighted analysis are nearly identical to the results from the standard analysis using the raw data (see Fig. S7 for a summary). We therefore report only the standard unweighted analysis in the main text.

Scenario calibration. In this experiment, all participants responded to the same questions used for the scenario calibration in Experiment 1. Figure 2 shows the results for both samples combined (center panel), and the US and UK (bottom left and right) separately. Although there is variability between participants and samples, people on average again perceived the scenarios as intended along a $2 \times 2$ factorial structure.

Procedure. Upon providing informed consent, participants first responded to demographic items (age and gender), and then indicated their political leaning using a single item with an 11point response scale from $1=$ Very left/liberal to $11=$ Very right/conservative. Our item was identical to those used in various national election studies, such as the British Election Study (BES) of 2019 (Fieldhouse et al., 2021), and the American National Election Survey of 2020 (American National Election Studies, 2021).

Participants were then shown one of the four future scenarios at random and responded to the same three questions as in Experiment 1 about own want, likelihood, and others want. The scenario remained visible while people responded to those three questions.

The scenario was then removed and participants responded to the two items about the nature of the scenario that were used for calibration in Experiment 1. Finally, participants were again asked if they had put in a reasonable effort. No participants indicated that they were not paying attention.

Analysis. Because unlike in Experiment 1, the procedure was identical for both samples, and because participants in the U.S. and UK were tested only a few days apart, omnibus analyses were conducted for both samples that included country as a further factor. Responses to the three main questions (own want, likelihood, others want) were thus analyzed by separate $2 \times 2 \times 2$ between-participants analyses of variance (ANOVAs) using the lm function in $\mathrm{R}$, with the two experimental factors and country as the three independent variables. All factors were coded as Helmert contrasts (i.e., zero-centered coefficients). We used the
Anova function from the car package to obtain Type 3 sums of squares, which are preferable because they are conditioned on all other effects in the model. As this experiment did not involve repeated measures and all statistical comparisons were betweensubjects, mixed-effect modeling was not possible or required.

Analogous to the simple models in Experiment 1, we first present the $2 \times 2 \times 2$ ANOVAs, before we examine whether the inclusion of political leanings as a potential covariate or moderator leads to an improved fit of the model. Given that the effects of demographic covariates were modest, relatively inconsistent, and hence fairly uninteresting in Experiment 1, we elected not to repeat a similar analysis for this experiment. Instead, we focused exclusively on political leaning and explored its role in a moderated regression analysis. The political leanings scores were zero-centered for all analyses but are plotted using the original 1-11 scale. We report only strictly significant effects (i.e., $p<0.05)$ in the main text, with the complete ANOVA tables for the simple models relegated to the online supplement (Table S11).

\section{Results}

What did people want to happen in the future?. The top panels in Fig. 6 show that in replication of Experiment 1, people in both countries preferred the progressive scenarios over a return to normal, and they preferred a redistribution of power to people and away from government. The $2 \times 2 \times 2$ ANOVA for own want confirmed this obvious pattern with a main effect of orientation, $F(1,791)=21.55, \mathrm{MSE}=8.85, p<0.001, \hat{\eta}_{G}^{2}=0.027$, and a main effect of distribution of power, $F(1,791)=68.59, \mathrm{MSE}=8.85$, $p<0.001, \hat{\eta}_{G}^{2}=0.080$. None of the other effects in the ANOVA were significant.

We next explored whether adding political leaning as a continuous predictor added explanatory power to the analysis. We compared various models that included political leaning and found that a moderation model in which political leaning interacted with all three experimental factors (orientation, distribution of power, and country) fit considerably better than other, more constrained models $(F(8,783)=8.28, p<0.0001$, when the fully interactive model is compared to the model with the three factors only).

This complex model again yielded main effects of orientation, $F(1,783)=24.41, \mathrm{MSE}=8.24, p<0.001, \hat{\eta}_{G}^{2}=0.030$, and distribution of power, $F(1,783)=68.26, \mathrm{MSE}=8.24, p<0.001$, $\hat{\eta}_{G}^{2}=0.080$. In addition, political leaning had a significant effect on its own, $F(1,783)=16.02, \mathrm{MSE}=8.24, p<0.001, \hat{\eta}_{G}^{2}=0.020$, and it also interacted with orientation, $F(1,783)=31.90$, $\mathrm{MSE}=8.24, p<0.001, \hat{\eta}_{G}^{2}=0.039$, as well as with distribution of power, $F(1,783)=9.99, \mathrm{MSE}=8.24, p=0.002, \hat{\eta}_{G}^{2}=0.013$. No other effects were significant. The bottom panel of Fig. 6 illustrates the two interactions involving political leaning. It is clear that political leaning played a substantial role for the back to normal scenarios, with people on the political right being more in favor than people on the left. The effect of political leaning was much attenuated for the progressive scenarios. In addition, people on the left were less sensitive to the distribution of power than people on the right, who preferred individual autonomy over strong government to a greater extent.

The strong role of political views in people's desires for the future invites two important follow-up questions: First, are the observed effects contingent on the over-representation of people on the political left in our samples? Second, across what range of the political spectrum are the observed effects manifest? The first question is answered by the weighted analysis in the supplement, which confirmed that the main effects for orientation and distribution of power persist in both samples even if observations 


\section{Distribution of power $\$$ Individual autonomy $\$$ Strong government}

\section{Own want US}

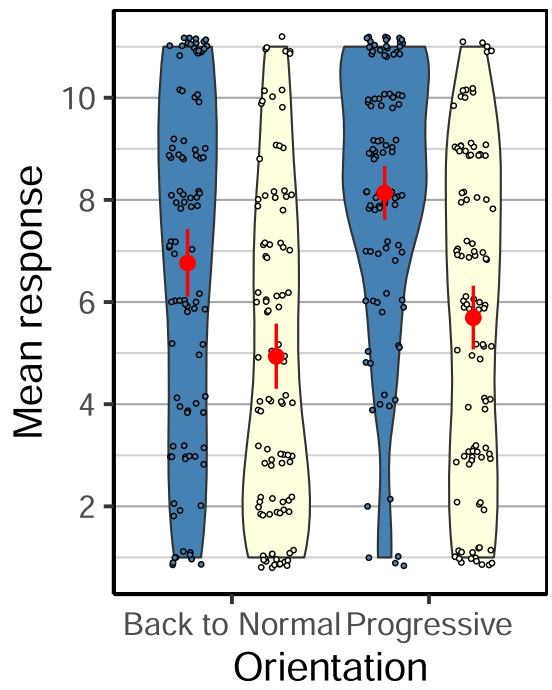

Own want UK

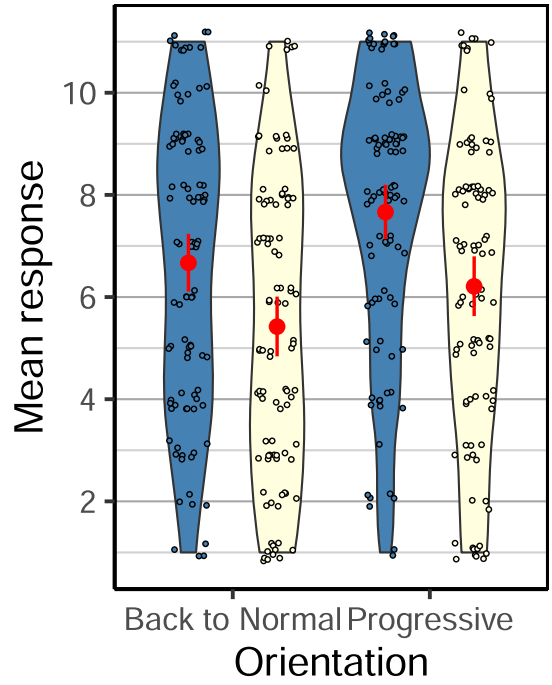

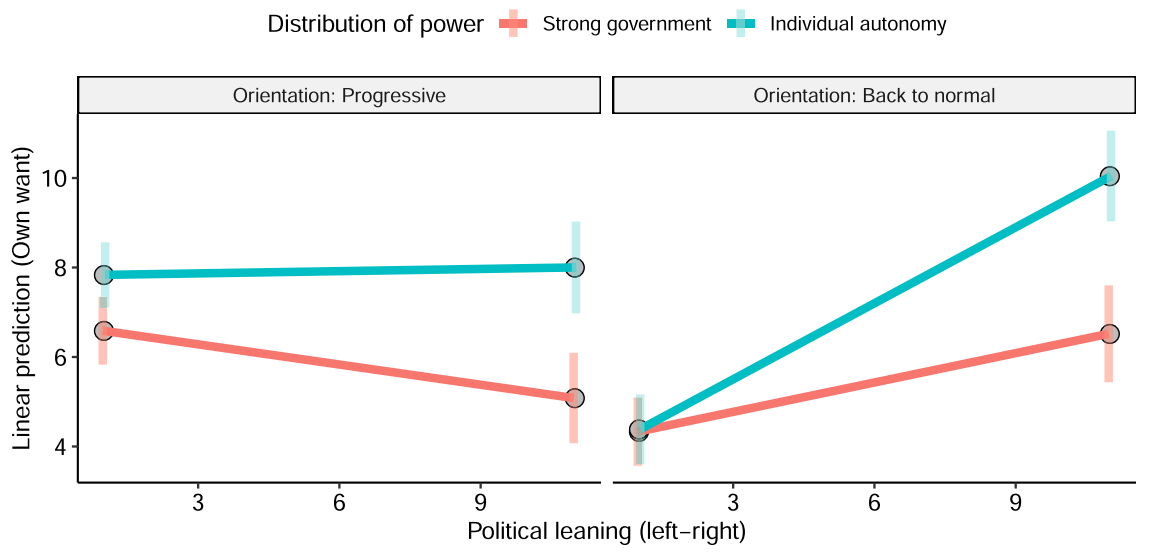

Fig. 6 Experiment 2: People's own preferences for the scenarios as a function of the experimental variables. Top left panel shows data for the US sample and the top right panel shows responses for the U.K. sample. The red plotting symbols and error bars represent means and $95 \%$ confidence intervals. Data are jittered to avoid overprinting. The bottom panel shows estimated marginal means of the linear trends for political leaning (obtained by $\mathrm{R}$ package emmeans) broken down by experimental variables but averaged across samples.

are weighted to reflect the estimated population distribution of political leanings (see Tables S12 and S15). These results re-affirm our conclusion that, overall, people prefer the progressive scenarios over a return to normal, and they prefer individual autonomy over power being retained by governments. The second question was answered by a floodlight analysis (Johnson and Neyman, 1936, Spiller et al., 2013), which establishes regions of significance for a moderator variable in which two experimental groups differ significantly from each other. We used the johnson_neyman function of the $\mathrm{R}$ package interactions to perform a floodlight analysis, with the results shown in Fig. 7. The figure shows that people preferred scenarios involving individual autonomy over the government retaining power across the entire political spectrum (top row of panels), with the exception of far-left participants who were indifferent to the distribution of power when the future involved a return to normal. By contrast, the preference for a progressive future was limited to people on the political left and center (bottom row of panels; note that this is expressed as a negative preference for a return to normal), with center-right and right-wing participants being largely indifferent about whether the future should be progressive or involve a return to normal. One exception to this indifference was observed for people on the far right, who favored a return to normal over a progressive future if it involved individual autonomy.

Our combined interpretation of the weighted analysis and the floodlight analysis is that overall people prefer a progressive future over a return to normal, even when the samples are reweighted to conform to the known distribution of political leanings in the UK and US. A progressive future thus constitutes a majoritarian preference in both countries. However, when that preference is further broken down by political leaning, it is found to be strongest on the political left and center-left, whereas people on the center-right are largely indifferent (with an additional pocket of opposition on the far right, but only for the scenario involving individual autonomy). The overall preference thus results from a strong preference to the left of center combined with (mainly) indifference to the right of center.

What did people think would happen?. As in Experiment 1, people's anticipation for the future differed considerably from their own preferences. As shown in Fig. 8, people in both countries thought 
Orientation: Progressive

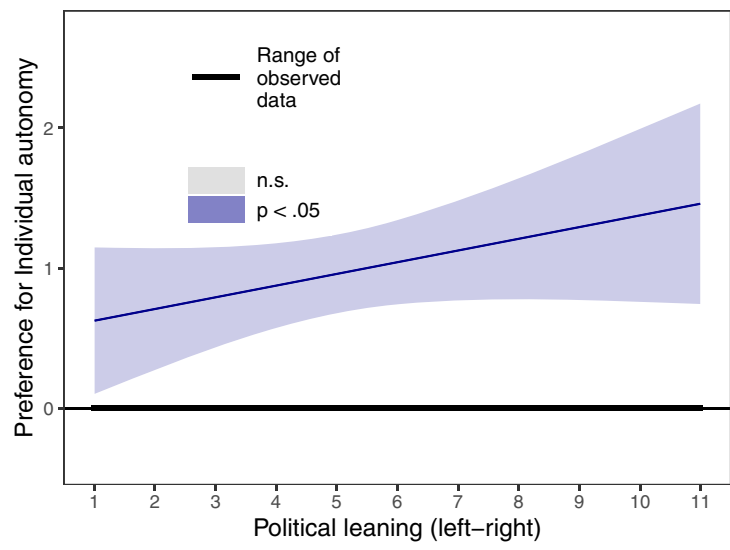

Distribution of Power: Government

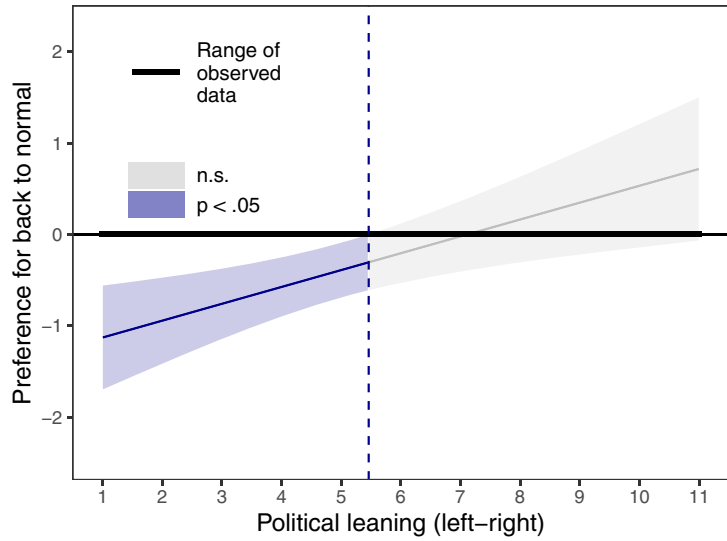

Orientation: Back to normal

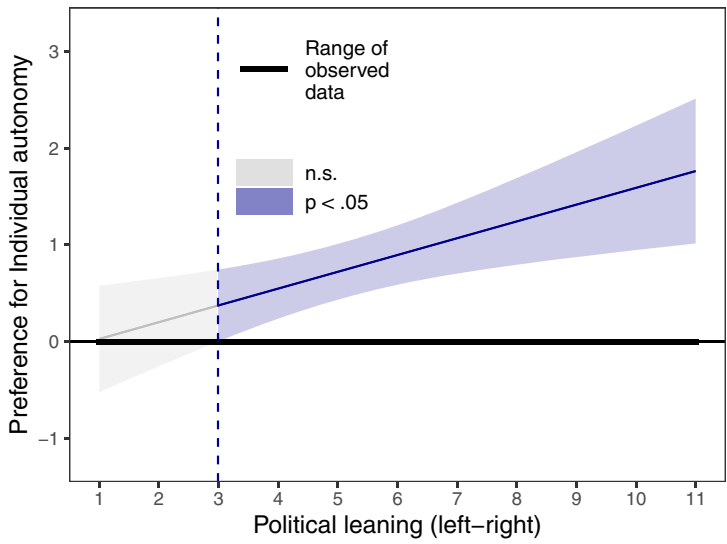

Distribution of Power: People

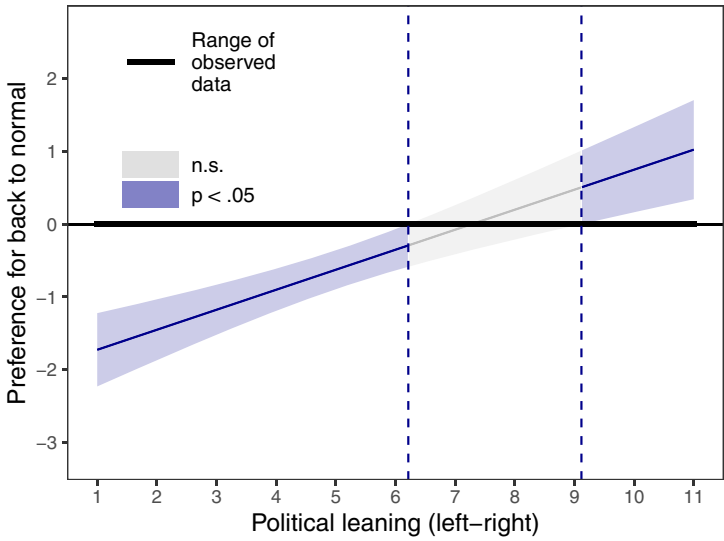

Fig. 7 Floodlight analysis in Experiment 2. In each panel, people's preferences for the future (expressed as difference score between two scenarios) are expressed as a function of political leaning. The top row of panels shows preferences for individual autonomy and a return of power to the people (as opposed to power being retained by governments) for the progressive (left) and back to normal scenarios (right). The bottom row of panels shows preferences for a return to normal (as opposed to a progressive future) when power is retained by government (left) or returned to people (right). In each panel, purple regions identify the range of political leanings where people's preferences for one over the other scenario are significant. Gray regions are indeterminate.

Distribution of power Individual autonomy Strong government

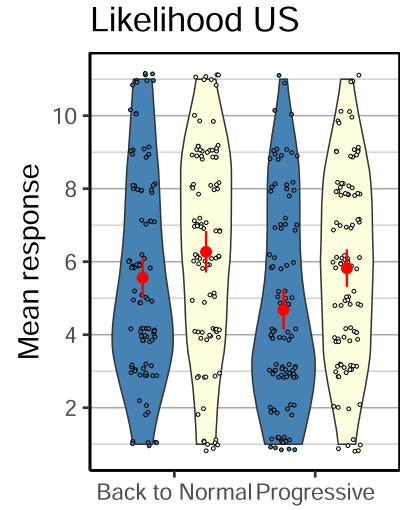

Orientation

\section{Likelihood UK}

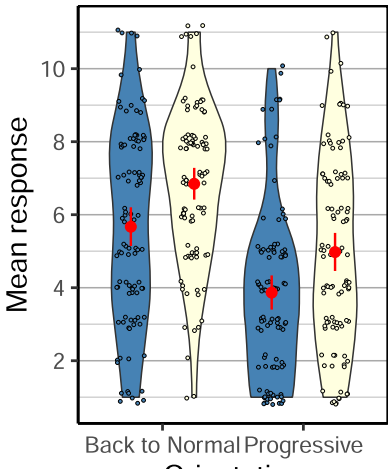

Orientation
Fig. 8 Experiment 2: People's judged likelihood of the scenarios as a function of the experimental variables. Left panel shows data for the US sample and the right panel shows data for the U.K. sample. The red plotting symbols and error bars represent means and 95\% confidence intervals. Data are jittered to avoid overprinting. that a return to normal was more likely than a progressive future, and they also felt it was more likely that the government would retain its power rather than restoring individual autonomy. The $2 \times 2 \times 2$ ANOVA confirmed this obvious pattern with a main effect of orientation, $F(1,791)=45.53$, MSE $=6.87, p<0.001, \hat{\eta}_{G}^{2}=0.054$, and a main effect of distribution of power, $F(1,791)=31.06$, $\mathrm{MSE}=6.87, p<0.001, \hat{\eta}_{G}^{2}=0.038$. In addition, the interaction between country and orientation was significant, $F(1,791)=9.96$, $\mathrm{MSE}=6.87, p=0.002, \hat{\eta}_{G}^{2}=0.012$, reflecting the fact that whereas American and British participants differed little in their perceived likelihood of the government retaining power, people in the UK felt that individual autonomy was even less likely than their counterparts in the US.

A complex model in which political leaning was introduced as a covariate and potential moderator and interacted with all three experimental factors (orientation, distribution of power, and country) again fit significantly better than the simple $2 \times 2 \times 2$ ANOVA, $F(8,783)=2.10, p<0.03$, although the gain was modest compared to the own want analysis. This complex model again yielded main effects of orientation, $F(1,783)=46.45, \mathrm{MSE}=6.79$, $p<0.001, \hat{\eta}_{G}^{2}=0.056$, and distribution of power, $F(1,783)=32.78$, 
Distribution of power Individual autonomy Strong government

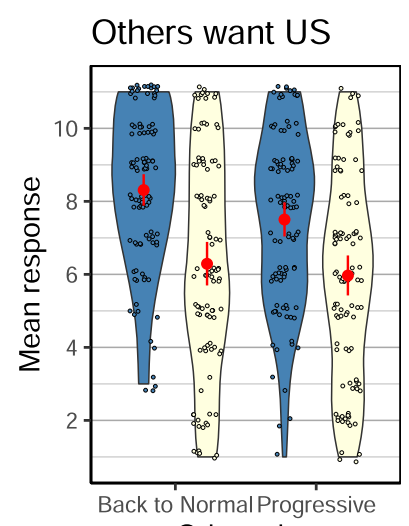

Orientation

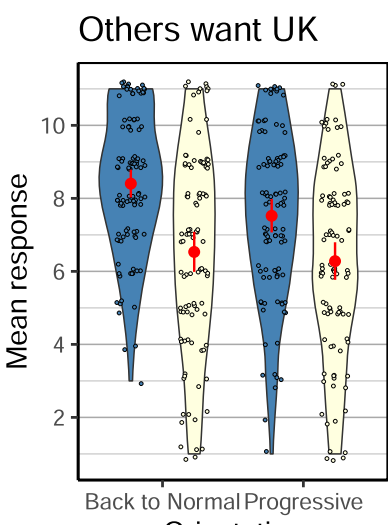

Orientation

Fig. 9 Experiment 2: People's perceived preferences of others for the scenarios as a function of the experimental variables. The left panel shows responses for the US sample and the right panel shows responses for the UK sample (top right). The red plotting symbols and error bars represent means and 95\% confidence intervals. Data are jittered to avoid overprinting.

MSE $=6.79, p<0.001, \hat{\eta}_{G}^{2}=0.040$, as well as an interaction between country and orientation, $F(1,783)=9.02, \mathrm{MSE}=6.79, p=0.003$, $\hat{\eta}_{G}^{2}=0.011$. In addition, political leaning was a significant covariate on its own, $F(1,783)=5.41, \mathrm{MSE}=6.79, p=0.020, \hat{\eta}_{G}^{2}=0.007$, suggesting that people on the political right were generally more confident in their expectations for the future.

What did people think others wanted from the future? People's perceptions of what others in their country wanted for the future are shown in Fig. 9. People again thought that others did not share their own preferences for a progressive future, although they correctly estimated others to prefer individual autonomy to a strong government. The $2 \times 2 \times 2$ ANOVA confirmed the pattern with a main effect of orientation, $F(1,791)=10.20, \mathrm{MSE}=6.27$, $p=0.001, \hat{\eta}_{G}^{2}=0.013$, and a main effect of distribution of power, $F(1,791)=88.50, \mathrm{MSE}=6.27, p<0.001, \hat{\eta}_{G}^{2}=0.101$. No other terms were significant. Inclusion of political leaning did not improve explanatory power, with the most complex fully interactive model failing to fit signicantly better than the simple model, $F(8,783)=1.78, p<0.08$.

The main effect of orientation accentuates the observation from Experiment 1 that people underestimate popular support for the progressive futures they themselves prefer. In this experiment, the underestimate was sufficiently strong for people to presume that others want a return to normal significantly more than a progressive future.

\section{General discussion}

Limitations. We explored a complex and nuanced landscape of possible futures and how people feel about them. No single article can fully explore this landscape, and so even though our investigation spanned more than a year and sampled people from two different countries, several limitations deserve to be highlighted. First, we did not step out of the "Anglosphere" and it is entirely possible that the publics in other countries will have very different hopes and anxieties for the future.

Second, although our sample was representative of the British and American population on several relevant dimensions (Tables S1 and S3), the panel provider does not ensure a politicallyrepresentative sample. Indeed, we found that our UK sample was slightly biased to the political left compared to a large-scale

British election study that used the same item to probe political leaning. The bias in the US sample was even greater in comparison to the American National Election Study. When these sampling biases were corrected through a raking procedure, our main results and conclusions remained unchanged (Fig. S7). We therefore do not believe that our conclusions are compromised by the political bias in our samples.

Finally, although we collected open-ended qualitative responses in Experiment 1, in both experiments we also presented participants with 4 predefined scenarios. Those scenarios were crafted to instantiate two important and highly prominent streams of public debate about the future, but that does not mean the scenarios spanned the entire range of plausible futures. All our scenarios presented relatively linear extrapolations from the present and none foresaw cataclysmic tipping points or further economic calamities. We also did not delve deeply into other crucial issues for the future, such as inequality (MillwardHopkins, 2021). It remains for future research to explore people's thoughts about those other potential futures and nonlinearities.

Notwithstanding these caveats, our work has provided several novel insights. We explore these insights and the policy implications of our research next.

Summary and relationship to previous work. We highlight six aspects of our results. First, the open-ended responses in Experiment 1 identified the strong sense of loss suffered by many participants, in particular involving social interactions with friends and family and the lost freedom to travel. The responses also identified several silver linings; that is, people were hoping for some things to stay different after the pandemic, such as working from home or reduced commuting. These results mesh well with findings from New Zealand (Every-Palmer et al., 2020), which showed that people suffered profound losses during the lockdown, combined with similar silver linings.

Second, in the quantitative analyses of both experiments, the silver linings arguably translated into people's preference for a progressive future, with a commitment to sustainability and fairness, over a return to normal. This preference for a progressive future was common to both countries and it was shared even by people who did not identify anything worth retaining from their changed life during the pandemic. The preference was also remarkably stable over time (Experiment 2 was conducted more than a year after Experiment 1) and it was not affected by the particulars of the experimental design (withinsubjects vs. between-subjects) and the precise wordings of the scenarios. The temporal stability is particularly remarkable in light of the fact that the intervening year included a devastating second wave of the pandemic, the arrival of vaccines, and (in the US) a major political shift. An important qualification to this generality is that the preference for a progressive future is associated with people's political leanings. It is mainly people on the center-left and left who preferred the progressive scenarios to a return to normal, with people on the right being mainly indifferent to those two possible futures. Opposition to a progressive future was limited to the extreme right and then only for the individual autonomy scenario. The fact that people on the right were mainly indifferent, rather than implacably opposed, to a progressive future may appear surprising at first glance, although it meshes well with other recent data from the UK that also showed broad cross-party support for environmental prioritization (Kenward \& Brick, 2021). It is important to underscore that we cannot attribute causality to the association between political leanings and preferences for different scenarios. For example, it is entirely plausible that a preference for a particular scenario affects political leanings. If political parties 
become associated with particular narratives-for example, if a progressive fairer future is associated with the language of the left -then it is possible that people who prefer that future also become more likely to self-identify as left. The direction of causality is therefore unclear. The main issue, therefore, is not whether people of the left or right prefer one or the other scenario, but what the overall consensus is and what the level of support in the population is for these views.

Third, somewhat unexpectedly, moral values (MFQ in Experiment 1, US sample), did not play a major role in determining people's preferences. Although some subscales were associated with people's own wants and perceived likelihood in a readily explainable manner (e.g., the more Americans endorsed compassion the more likely they were to prefer the progressive scenarios), the overall effect sizes were modest and when corrected for complexity (via BIC), there was little support for the inclusion of covariates in any of the statistical models in Experiment 1.

Fourth, people in both experiments thought that their desires for the future were unlikely to materialize. In both studies, people preferred progressive futures to a return to normal, but in both studies people judged a return to normal to be more likely. People also generally preferred a future with individual autonomy over one with strong government control, and they again thought that this preference was unlikely to materialize. (This pattern was particularly clear in Experiment 2 but generally also applied to at least one of the samples in Experiment 1). It is notable that this skepticism about the future persisted over more than a year between experiments and, if anything, grew stronger. Given that a previous worldwide upheaval, the global financial crisis of 2008, engendered only minimal reform (Alves and Kvangraven, 2020), people's expectation of a return to normal after the pandemic might reflect an extrapolation from lived historical experience. People's skepticism about a progressive future can arise from a number of variables, from doubts about its technological or financial viability to doubts about political achievability. The financial viability of a progressive future is impossible to ascertain with certainty. However, at least one economic analysis has found a post-COVID future that tackles climate change to be achievable in terms of debt sustainability (Ruiz \& Stupariu, 2021).

Fifth, people overestimated others' presumed preferences for a return to normal. In Experiment 1, participants thought that others wanted a return to normal as much (US) or nearly as much (UK) as a progressive future. In Experiment 2, this overestimation was accentuated further and participants in both countries thought that others wanted a return to normal more than a progressive future. This striking divergence between what people actually want (a progressive future), what they expect to get (a return to normal), and what they think others want (overestimated support for a return to normal) represents an instance of pluralistic ignorance-the majority of people who want a progressive future think they are in the minority (Shamir \& Shamir, 1997; Todorov \& Mandisodza, 2004). Pluralistic ignorance can have politically problematic consequences. In the long term, people tend to shift their attitudes or behaviors in the direction of what they perceive to be the prevailing majority opinion (even if it is not) (Botvin et al., 1992; Eisner et al., 2020, Prentice et al., 1993). It follows that the preferences we observed here may turn out to be transient, and that a return to normal will become more acceptable in future, not because people desired this outcome but because they felt it was inevitable and that others wanted it, thereby triggering a process of attitude adjustment. Ultimately, this process would mean that people's actual preferences never find the political expression that they deserve in a democracy. The entanglement between people's hopes for the future and the behavior of others was also revealed in the open- ended responses. The predominance of phrases such as people should ... highlighted what others should do, or were feared not to do, thereby reflecting a general anxiety about others and a concern that one's own wants were unusual or perhaps even deviant. Those responses reflect the opposite of empowerment to shape one's own future, considering the future instead as something engineered by unspecified others.

Finally, we suggest that people's responses were not only remarkably stable over time but also differed little between these countries. Although there are subtle differences between American and British respondents, in particular in Experiment 1, the similarities are striking. In Experiment 2, there was only a single significant effect involving country (the interaction between country and orientation for perceived likelihood), out of 12 component terms involving country across the three simple ANOVAs. The large degree of overlap between public opinion in the two samples is helpful when considering the implications of our findings for policy.

Implications for policy. Our findings suggest the urgent need to shift away from narratives that foreground failure of sustainability-focused policies, denial (e.g., of climate change), resistance to societal change, and catastrophes (O'Neill et al., 2009), towards communication strategies that make visible the high levels of desire for sustainable and equitable futures, which in our case extended across more than a year during the pandemic and which does not appear to be politically highly polarized (although more actively endorsed by people on the centerleft and left and weakly opposed by others). Narratives should emphasize the number of citizens already interested in and hoping to see and create sustainable futures. There is evidence that informing people about the actual social consensus on climate change increases support for pro-climate policies (Mildenberger \& Tingley, 2019). There is also a large body of literature showing that informing people of the scientific (as opposed to social) consensus on climate change is nudging them towards acceptance of the scientific findings and support of climate mitigation (Lewandowsky et al., 2013; van der Linden et al., 2019; Maertens et al., 2020; van der Linden, 2021). Communicating a social or scientific consensus is not merely a necessary countermeasure to the pluralistic ignorance we observed here: It is also advisable because motivation increases if personal wants and goals are shared by others (Fishbach et al., 2016). Merely informing people of the actual social consensus for a progressive future may thus help unleash the motivation needed to achieve it.

The first concrete step for policy might therefore be to create the conditions necessary for citizens in today's highly polarized societies-the US foremost among them-to resume constructive communication with each other (Putnam, 2020). Recent research on deliberative fora (Suiter et al., 2016) and digital architectures that support respectful dialog (Esau et al., 2017) are signposts in that direction. This is especially important because perceived polarization leads to reduced trust in leaders and fellow citizens, promotes selfish actions, and contributes to expectations of a bleak future (Jetten et al., 2020).

Subsequently, it might be useful to focus public discourse on the similarities between the challenges of COVID-19 and climate change. This could highlight how reflecting on our response to one challenge can inform our response to the other; for example, the costs of delaying action can far outweigh the costs of early intervention in both cases (Manzanedo \& Manning, 2020). This discourse should also center on our ability to act, both individually and collectively, which can feed into feelings of hope that can fuel action (Geiger et al., 2021; Ojala, 2012). The pandemic has shown that broad support for inconvenient 
measures can be achieved if the measures are seen as effective in mitigating an imminent threat (Kallbekken \& Sælen, 2021). The strong (overall) endorsement of a progressive vision for the future (including the weak levels of opposition on the political right) should encourage policymakers to be bold and decisive in their negotiations and their actions.

\section{Data availability}

Deanonymized data, analysis scripts, and the markdown files for this manuscript can be found at https://osf.io/ $6 \mathrm{nkmh} /$. When downloaded onto a Windows machine with $\mathrm{R}$ and Rstudio installed, the files are set up to allow all analyses and the final manuscript to be compiled by the user.

Received: 30 January 2021; Accepted: 26 October 2021; Published online: 25 November 2021

\section{References}

Alves C, Kvangraven IH (2020) Changing the narrative: Economics after Covid-19. Rev Agrar Stud 10:147-163

American National Election Studies (2021) ANES 2020 time series study full release [dataset and documentation]. Retrieved from https:// electionstudies.org/data-center/2020-time-series-study/

Bartik AW (2020) The impact of COVID-19 on small business outcomes and expectations. Proc Natl Acad Sci 117:17656-17666

Bates D, Mächler M, Bolker B, Walker SC (2015) Fitting linear mixed-effects models using lme4. J Stat Softw 67:1-48

Bohr J (2014) Public views on the dangers and importance of climate change: Predicting climate change beliefs in the United States through income moderated by party identification. Clim Change 126:217-227

Bonaccorsi G et al. (2020) Economic and social consequences of human mobility restrictions under COVID-19. Proc Natl Acad Sci USA 117:15530-15535

Botvin GJ, Botvin EM, Baker E, Dusenbury L, Goldberg CJ (1992) Psychol Rep 70:171-178

Bouman T, Steg L, Dietz T (2021) Insights from early COVID-19 responses about promoting sustainable action. Nat Sustain 4:194-200

Brauer M, Curtin JJ (2018) Linear mixed-effects models and the analysis of nonindependent data: A unified framework to analyze categorical and continuous independent variables that vary within-subjects and/or within-items. Psychol Method 23:389-411

Clark H, Gruending A (2020) Invest in health and uphold rights to "build back better" after COVID-19. Sex Reprod Health Matters 28:1781583

Ecker UKH et al. (2020) Using the COVID-19 economic crisis to frame climate change as a secondary issue reduces mitigation support. J Environ Psychol 70:101464

Economist Intelligence Unit (2020) Democracy index 2019: a year of democratic setbacks and popular protest. The Economist

Eisner L, Spini D, Sommet N (2020) A Contingent Perspective on Pluralistic Ignorance: When the Attitudinal Object Matters. Int J Public Opin Res 32:25-45

Engler S et al (2021) Democracy in times of the pandemic: explaining the variation of COVID-19 policies across European democracies. West European Politic

Esau K, Friess D, Eilders C (2017) Design matters! an empirical analysis of online deliberation on different news platforms. Policy Internet 9:321-342

European Commission. (2020). Europe's moment: Repair and prepare for the next generation. Retrieved from https:/ec.europa.eu/commission/presscorner/ detail/en/IP_20_940

Every-Palmer S et al. (2020) Psychological distress, anxiety, family violence, suicidality, and wellbeing in New Zealand during the COVID-19 lockdown: a cross-sectional study. PLoS ONE 15:e0241658

Fieldhouse E et al (2021) 2019 BES post-election random probability survey v.1.1.1. British Election Study. Retrieved from https://www.britishelectionstudy.com/ data-objects/cross-sectional-data/

Fischer A, Peters V, Vávra J, Neebe M, Megyesi B (2011) Energy use, climate change and folk psychology: Does sustainability have a chance? Results from a qualitative study in five European countries. Glob Environ Change 21:1025-1034

Fishbach A, Steinmetz J, Tu Y (2016) Motivation in a social context. In: Advances in motivation science (pp. 35-79). Elsevier

Freedom House (2020) Freedom in the world 2020. A leaderless struggle for democracy

Geiger N, Swim JK (2016) Climate of silence: pluralistic ignorance as a barrier to climate change discussion. J Environ Psychol 47:79-90
Geiger N, Gore A, Squire CV, Attari S (2021) Investigating similarities and differences in individual reactions to the COVID-19 pandemic and the climate crisis. Clim Change 167. https://doi.org/10.1007/s10584-021-03143-8

Gelman A, Carlin J (2014) Beyond power calculations. Perspect Psychol Sci 9:641-651

Goede M (2020) COVID-19 and change. Arch Bus Res 8:311-370

Goldberg MH, Linden Svander, Leiserowitz A, Maibach E (2020) Perceived social consensus can reduce ideological biases on climate change. Environ Behav 52:495-517

Graham J et al. (2011) Mapping the moral domain. J Person Soc Psychol 101:366-385 Green P, MacLeod CJ (2016) SIMR : An R package for power analysis of generalized linear mixed models by simulation. Method Ecol Evol 7:493-498

Greenaway C et al (2020) COVID-19: exposing and addressing health disparities among ethnic minorities and migrants. J Travel Med 27. https://doi.org/ $10.1093 / \mathrm{jtm} / \mathrm{taaa} 113$

Grogan J (2020) States of emergency. Eur J Law Reform 22:338-354

Hamann R (2020) The promise and peril of "building back better". Environ: Sci Policy Sustain Dev 62:41-50

Hamilton LC (2011) Education, politics and opinions about climate change evidence for interaction effects. Clim Change 104:231-242

Harmer A et al. (2021) It's time for the health community to back a Green New Deal. BMJ. Retrieved from https://blogs.bmj.com/bmj/2021/04/15/its-timefor-the-health-community-to-back-a-green-new-deal/

Haug $\mathrm{N}$ et al. (2020) Ranking the effectiveness of worldwide COVID-19 government interventions. Nat Hum Behav 4:1303-1312

Holmes DS (1968) Dimensions of projection. Psychol Bull 69:248-268

Jetten J, Reicher SD, Haslam SA, Cruwys T (2020). Together apart: the psychology of COVID-19. Sage, Thousand Oaks, CA

Johnson PO, Neyman J (1936) Tests of certain linear hypotheses and their application to some educational problems. Stat Res Memoir 1:57-93

Kallbekken S, Sælen H (2021) Public support for air travel restrictions to address COVID-19 or climate change. Transport Res Part D: Transport Environ 93:102767

Kavanagh MM (2020) Authoritarianism, outbreaks, and information politics. Lancet Public Health 5:e135-e136

Kenward B, Brick C (2021) Even conservative voters want the environment to be at the heart of post-COVID-19 economic reconstruction in the UK. J Soc Polit Psychol 9:321-333

Krange O, Kaltenborn BP, Hultman M (2018). Cool dudes in Norway: Climate change denial among conservative Norwegian men. Environ Sociol https:// doi.org/10.1080/23251042.2018.1488516

Leviston Z, Walker I, Morwinski S (2013) Your opinion on climate change might not be as common as you think. Nat Clim Change 3:334-337

Lewandowsky S, Gignac GE, Vaughan S (2013) The pivotal role of perceived scientific consensus in acceptance of science. Nat Clim Change 3:399-404

Lewandowsky S, Cook J, Fay N, Gignac GE (2019) Science by social media: Attitudes towards climate change are mediated by perceived social consensus. Memory Cogn 47:1445-1456

Lührmann A, Lindberg SI (2020) Autocratization surges-Resistance grows. Democracy Report 2020. Gothenburg: V-Dem Institute

Maertens R, Anseel F, van der Linden S (2020) Combatting climate change misinformation: evidence for longevity of inoculation and consensus messaging effects. J Environ Psychol https://doi.org/10.1016/j.jenvp.2020.101455

Maerz SF, Lührmann A, Lachapelle J, Edgell AB (2020). Worth the sacrifice? Illiberal and authoritarian practices during covid-19. SSRN Electron J https:// doi.org/10.2139/ssrn. 3701720

Mair S (2020) What will the world be like after coronavirus? Four possible futures. The Conversation. Retrieved from https://theconversation.com/what-willthe-world-be-like-after-coronavirus-four-possible-futures-134085

Manzanedo RD, Manning P (2020) COVID-19: Lessons for the climate change emergency. Sci Total Environ 742:140563

Maravall JM (1994) The myth of the authoritarian advantage. J Democracy 5:17-31

Mayor of London (2020) Mayor invests $€ 10 \mathrm{~m}$ in Green New Deal to secure thousands of green jobs. Retrieved from https://www.london.gov.uk/pressreleases/mayoral/mayor-invests-10m-in-green-new-deal-to-save-jobs

McCright AM (2010) The effects of gender on climate change knowledge and concern in the American public. Popul Environ 32:66-87

Mildenberger M, Tingley D (2019) Beliefs about climate beliefs: The importance of second-order opinions for climate politics. Br J Polit Sci 49:1279-1307

Millward-Hopkins J (2021) Back to the future: Old values for a new (more equal) world. Futures 128:102727

Morris HE (2021) Constructing the millennial "other" in United States press coverage of the Green New Deal. Environ Commun 15:133-143

Mullen B (1985) The false consensus effect: A meta-analysis of 115 hypothesis tests. J Exp Soc Psychol 21:262-283

O'Neill S, Nicholson-Cole S (2009) Fear won't do it": Promoting positive engagement with climate change through visual and iconic representations. Sci Commun 30:355-379 
Ojala M (2012) Hope and climate change: The importance of hope for environmental engagement among young people. Environ Educ Res 18:625-642

Paltiel AD, Schwartz JL, Zheng A, Walensky RP (2020). Clinical outcomes of a COVID-19 vaccine: Implementation over efficacy. Health Affair 40. https:// doi.org/10.1377/hlthaff.2020.02054

Pearson AR, Schuldt JP, Romero-Canyas R, Ballew MT, Larson-Konar D (2018) Diverse segments of the US public underestimate the environmental concerns of minority and low-income Americans. Proc Natl Acad Sci 115:12429-12434

Peer E, Brandimarte L, Samat S, Acquisti A (2017) Beyond the Turk: Alternative platforms for crowdsourcing behavioral research. J Exp Soc Psychol 70:153-163

Prentice DA, Miller DT (1993) Pluralistic ignorance and alcohol use on campus: Some consequences of misperceiving the social norm. J Person Soc Psychol 64:243-256

Putnam RD (2020) The upswing: how America came together a century ago and how we can do it again. Simon \& Schuster

Robinson LA, Sullivan R, Shogren JF (2020). Do the benefits of COVID-19 policies exceed the costs? Exploring uncertainties in the age-VSL relationship. Risk Anal. https://doi.org/10.1111/risa.13561

Rosner, D. (2020). Building back a better sustainable world. milbank quaterly opinion. https://doi.org/10.1599/mqop.2020.1202

Ross L, Greene D, House P (1977) The "false consensus effect": An egocentric bias in social perception and attribution processes. J Exp Soc Psychol 13:279-301

Ruiz JR, Stupariu P (2021) A green new deal and debt sustainability for the post COVID-19 world. Int Rev Appl Econ 35:288-307

Schwarz G (1978) Estimating the dimension of a model. Ann Stat 6:461-464

Serafini G et al. (2020) The psychological impact of COVID-19 on the mental health in the general population. QJM: Int J Med 113:531-537

Shamir J, Shamir M (1997) Pluralistic ignorance across issues and over time: Information cues and biases. Public Opin Quar 61:227-260

Shepherd DA (2020) COVID 19 and entrepreneurship: Time to pivot? J Manage Stud 57:1750-1753

Spiller SA, Fitzsimons GJ, Lynch JG, Mcclelland GH (2013) Spotlights, Floodlights, and the Magic Number Zero: Simple Effects Tests in Moderated Regression. J Market Res 50:277-288

Stott C, West O, Harrison M (2020) A turning point, securitization, and policing in the context of Covid-19: Building a new social contract between state and nation? Policing: J Policy Pract 14:574-578

Strauss A, Corbin J (1994) Grounded theory methodology. In: N. Denzin \& Y. Lincoln (eds.), Handbook of qualitative research, 1st edn. Sage, Thousand Oaks, CA, pp. 273-285

Suiter J, Farrell DM, O'Malley E (2016) When do deliberative citizens change their opinions? Evidence from the Irish Citizens' Assembly. Int Polit Sci Rev 37:198-212

Temple J (2020) We need economic relief now. Climate policy can come later. Technology Review. Retrieved from https://www.technologyreview.com/2020/03/24/ 950341/coronavirus-economic-stimulus-climate-policy-clean-energy-covid19/

The Lancet. The plight of essential workers during the COVID-19 pandemic. Lancet 395, 1587 (2020). https://doi.org/10.1016/S0140-6736(20)31200-9

Thomson S, Ip EC (2020) COVID-19 emergency measures and the impending authoritarian pandemic. J Law Biosci. https://doi.org/10.1093/jlb/lsaa064

Todorov A, Mandisodza AN (2004) Public opinion on foreign policy: The multilateral public that perceives itself as unilateral. Public Opin Quart 68:323-348

van Barneveld K et al. (2020) The COVID-19 pandemic: Lessons on building more equal and sustainable societies. Econ Labour Relat Rev 31:133-157

van der Linden S (2021) The gateway belief model (GBM): A review and research agenda for communicating the scientific consensus on climate change. Curr Opin Psychol. https://doi.org/10.1016/j.copsyc.2021.01.005

van der Linden S, Maibach E, Leiserowitz A (2019) Exposure to scientific consensus does not cause psychological reactance. Environ Commun, 1-8. https:// doi.org/10.1080/17524032.2019.1617763
Walsh MJ, Cantrell L (2020) The covid recovery must begin with climate action Bloomberg CityLab. Retrieved from https://www.bloomberg.com/news/ articles/2020-12-22/climate-fixes-can-help-cities-lead-covid-recovery

Wenham C, Smith J, Morgan R (2020) COVID-19: The gendered impacts of the outbreak. Lancet 395:846-848

Xiong J et al. (2020) Impact of COVID-19 pandemic on mental health in the general population: A systematic review. J Affect Disord 277:55-64

Yong E (2020) How the pandemic will end. The Atlantic. Retrieved from https:// www.theatlantic.com/health/archive/2020/03/how-will-coronavirus-end/608719/

\section{Acknowledgements}

S.L. was supported by a Humboldt Research Award from the Humboldt Foundation in Germany during part of this work. K.F. was supported by the Zennström Initiative in Climate Change Leadership at Uppsala University. U.K.H.E. was supported by Australian Research Council grant FT190100708.

\section{Competing interests}

The authors declare no competing interests.

\section{Ethical approval}

The project received ethics approval from the University of Bristol (project ID 7196 and 8458). The project was conducted in accordance with the Declaration of Helsinki.

\section{Informed consent}

Participants provided informed consent via mouse click after reading an information section that was approved by the institutional ethics committee. Participants could withdraw from the study at any time by closing the browser tab.

\section{Additional information}

Supplementary information The online version contains supplementary material available at https://doi.org/10.1057/s41599-021-00961-0.

Correspondence and requests for materials should be addressed to Stephan Lewandowsky.

Reprints and permission information is available at http://www.nature.com/reprints

Publisher's note Springer Nature remains neutral with regard to jurisdictional claims in published maps and institutional affiliations.

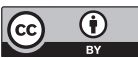

Open Access This article is licensed under a Creative Commons Attribution 4.0 International License, which permits use, sharing, adaptation, distribution and reproduction in any medium or format, as long as you give appropriate credit to the original author(s) and the source, provide a link to the Creative Commons license, and indicate if changes were made. The images or other third party material in this article are included in the article's Creative Commons license, unles indicated otherwise in a credit line to the material. If material is not included in the article's Creative Commons license and your intended use is not permitted by statutory regulation or exceeds the permitted use, you will need to obtain permission directly from the copyright holder. To view a copy of this license, visit http://creativecommons.org/ licenses/by/4.0/

(C) The Author(s) 2021 